\title{
The Effects of Soundscapes in Relieving Stress in an Urban Park
}

\author{
Xin Cao ${ }^{1,2, *(1)}$ and Yen Hsu ${ }^{1}$ (D) \\ 1 The Graduate Institute of Design Science, Tatung University, Taipei 104, Taiwan; yhsu@gm.ttu.edu.tw \\ 2 Fuzhou University of International Studies and Trade, Fuzhou 350202, China \\ * Correspondence: caoxin@fzfu.edu.cn; Tel.: +86-180-5040-2114
}

check for updates

Citation: Cao, X.; Hsu, Y. The Effects of Soundscapes in Relieving Stress in an Urban Park. Land 2021, 10, 1323. https://doi.org/10.3390/ land10121323

Academic Editors: Alexandru-Ionut Petrişor and Zhonghua Gou

Received: 25 September 2021 Accepted: 29 November 2021 Published: 1 December 2021 Retracted: 28 September 2022

Publisher's Note: MDPI stays neutral with regard to jurisdictional claims in published maps and institutional affiliations.

Copyright: (C) 2021 by the authors. Licensee MDPI, Basel, Switzerland. This article is an open access article distributed under the terms and conditions of the Creative Commons Attribution (CC BY) license (https:// creativecommons.org/licenses/by/ $4.0 /)$.

\begin{abstract}
Urban parks are important urban public spaces that guarantee people recreation, create positive emotions and relieve stress. Emerging research has shown that natural soundscapes are associated with restorative landscapes in urban parks. However, there is still a lack of knowledge on the use of physiological indexes to evaluate the effects of natural sounds versus human-based sounds on stress relief. In this study, the three physiological indexes of skin conductance level, heart rate and heart rate variability were collected in Fuzhou West Lake Park with the help of Ergo LAB data platform, and a soundscape perception evaluation questionnaire was used to assess the degree of soundscape perceptions in the sample sites. The differences in the stress relieving effects of different urban park environments were analysed by applying the median test, the Wilcoxon test was applied to analyse the effects of soundscapes and urban park environments on relieving stress, and regression analysis was used to identify the important factors of restorative soundscapes. The results found that urban park environments provide a certain degree of stress relief, but the stress relieving effects of different urban park environments vary and that natural spaces play an important role in relieving stress. Urban park soundscapes are key to restorative environmental design, with natural sounds such as birdsong and stream sound being important factors of restorative soundscapes.
\end{abstract}

Keywords: soundscape; urban park; relieving stress; skin conductance level; heart rate; heart rate variability

\section{Introduction}

The restorative effects of interaction with the natural environments have been extensively documented over the last 30 years since they were reported by Kaplan in 1989 [1]. By far, it is well known that the natural environments are more effective in promoting stress recovery than urban environments $[2,3]$. Soundscapes are acoustic environments that are perceived, experienced or understood by a person or group of people in the environment [4]. Previous research has concluded that the quality of soundscapes has significant effects on the environmental experience and relieving stress [5]. In addition, previous experiments have confirmed that exposure to restorative environments can help relieve stress [6].

During the COVID-19 pandemic, the public has become increasingly concerned about health and the quality of the living environment, and in this context, urban parks have become an important place for people to recreate [7]. The role of urban parks in promoting human health and well-being has been the focus of scholarly attention [8]. Urban parks are important urban public spaces that guarantee people relief from stress, with environmental and social benefits [9-11]. Compared to noisy urban environments, urban park environments create a more positive mood, give a sense of comfort, calm and relaxation, increase parasympathetic activity, inhibit sympathetic activity and reduce levels of salivary cortisol etc. These changes in physiological characteristics have been shown in previous studies to be indicative of stress relief [12-14]. However, most of the current studies have focused on visual perception, with very little research on the combination of visual and auditory 
perception $[15,16]$, the importance and impact of the urban park soundscapes are gradually being recognized [17].

People interact with space through their sense of hearing to form the soundscape of a particular space, i.e., the sound environment perceived, experienced or understood by an individual, group or community. Soundscapes are one of the main elements of restorative landscape design and have an important recreational value, and from a health perspective sound perception can be used as an enhancement tool for the human experience [18]. It has been shown that natural sounds such as birdsong are preferred to relieve stress, reduce anxiety and agitation and contribute to emotional recovery, and their restorative effects are supported by physiological indicators such as skin conductance level, heart rate and heart rate variability [19-22].

Noise is an important public health issue and the acoustic environment is an important factor in creating sustainable and healthy cities. Long-term exposure to noise can have both auditory and non-auditory effects on human health [23]. Noise-induced hearing loss is still very common in occupational settings and is increasingly caused by social noise exposure [24]. Noise has negative effects on human health, while natural soundscapes (e.g., birdsong) may have positive effects on recovery [18]. Research has shown that soundscapes can enhance the pleasantness of the human experience in urban spaces from a health-related perspective [25]. Recovery of skin conductance levels tends to be faster in natural sound environments compared to noisy environments, suggesting that natural sound facilitates recovery from sympathetic activity with psychological stress [25]. In a virtual natural environment, one's parasympathetic nerves are influenced by natural sounds, suggesting that stress relieving effects may occur in such an environment [19]. Among the sounds frequently found in urban park environments, the main ones include natural sounds, human-based sounds and mechanical sounds. Based on the results of previous studies quantified according to human comfort, this study classifies sounds that evoke positive human emotions as soundscapes and sounds that cause negative human emotions as noise [26].

Although a large number of studies have shown that natural sounds have a better restorative effect than human-based sounds, there is a lack of studies comparing different kinds of natural sounds or composite sound sources. For example, Wei Zhao et al. only reported the effects of birdsong on the restorative nature of urban parks [27], and Annerstedt et al. only demonstrated better stress relieving effects of birdsong and water flow sound exposure than no sound exposure [19]. While there are many studies on the subject of park soundscapes globally, there are still very few studies from Asia, especially those that take a multidimensional approach to the study of soundscapes. In addition, soundscape studies currently take little account of audiovisual interactions, and single-mode evaluations are always biased; the interaction of visual and auditory features can significantly influence environmental evaluations [28].

The importance of the soundscape quality of urban parks as one of the main environments for recreation in urban areas has been widely recognized [29]. The sound environment consists of a variety of sound sources, and it is the focus of this study to investigate the effect of multiple soundscapes on relieving stress. Restorative indexes of relieving stress include both psychological and physiological aspects, and this study focuses on measuring the effects of soundscapes on relieving stress through physiological indexes. In view of this, this study uses the West Lake Park in Fuzhou, China as the study site, selects representative urban park environmental sample sites with typical characteristics and extracts natural, human-based sounds and mechanical sounds from the urban park environments to collect three physiological indexes of skin conductance level, heart rate and heart rate variability and assess the degree of soundscape perception of the sample sites with the help of the Ergo LAB data platform and the soundscape perception evaluation questionnaire. The aim is to investigate the effect of soundscape on relieving stress in urban park environments, with a view to providing a reference for the design of 
restorative soundscapes in urban parks. As shown in Figure 1, the specific questions of this study are:

(1) Can urban park environments relieve stress?

(2) How do the stress relieving effects of different urban park environments vary?

(3) Do soundscapes have any effect on relieving stress in an urban park?

(4) If there are restorative soundscapes, which soundscapes are important factors in restorative soundscapes?

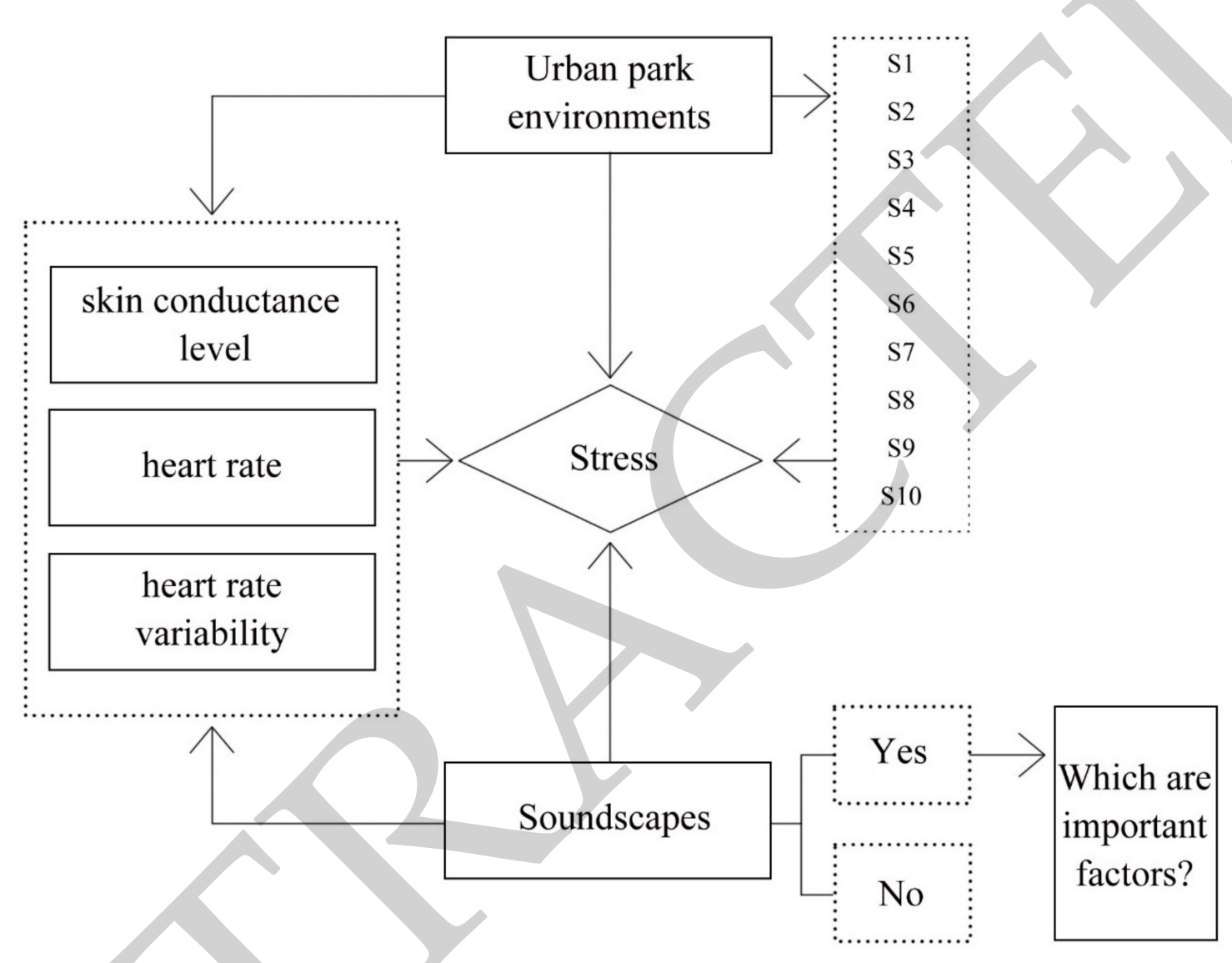

Figure 1. A conceptual framework of soundscape perception.

\section{Literature Review}

\subsection{Soundscape Research Methods}

In past studies, several methods for quantitative and qualitative measurement and assessment of urban soundscapes have been developed by researchers [30-35]. This illustrates that the assessment of the sound environment cannot be determined by simple measurements. ISO/TS 12913-3:2019 provides methods for the analysis of data collected in situ and supporting information [36].

Jahncke et al. studied the recovery effects of $7 \mathrm{~min}$ of exposure to audiovisual media of the river, audio media of the river only, silence or high office noise and participants reported that they had more energy than those who experienced only audiovisual media of the river [37]. It suggests that the experience of natural sounds by visual stimuli may relieve stress. Although the restorative effects of natural sounds from visual stimuli alone were reported by Ma et al. [38]. Furthermore, Alvarsson et al. reported faster recovery under natural than low-noise conditions, even though they were presented at the same sound pressure level (50 dB LAeq, $4 \mathrm{~min}$ ), suggesting that the difference between loudness and quietness of the acoustic environment may not be important factors in relieving stress [25]. Medvedev et al. observed that skin conductance levels decreased 
more rapidly when participants were exposed to bird and water sounds compared to sounds from the built environment [21]. Gould van Praag et al. found that participants who listened to familiar natural sounds showed better attentional monitoring and enhanced parasympathetic activity compared to those who listened to artificial sounds [39]. The above studies show that in some cases, natural sounds can produce restorative outcomes in emotional, psychological and physical terms.

For people living in urban centres, well-designed urban parks can provide a wide range of ecosystem services [40]. However, these benefits may be compromised by overexposure to noise, which can have a negative impact on human health [41]. Human perception of noise is not uniform and is largely dependent on the source of the noise and the subject who receives it [42]. Therefore, methods for measuring and assessing noise need to take into account the subjective effects associated with acoustic parameters, as well as the positive and negative effects of noise in terms of the acoustic quality of the urban environment [42]. Previous research has quantified sound according to human comfort levels, classifying sounds that evoke positive emotions as soundscapes and sounds that cause negative emotions as noise $[26,43,44]$.

Kang et al., (2016) proposed that psychoacoustic parameters (e.g., loudness, roughness, sharpness and fluctuating intensity) deal with the quantitative relationship between physical stimuli and the auditory sensations induced by them [45]. Fiebig et al., (2009) suggest that the parameters of hearing are related to the perceptible patterns in the sound signal [46]. On the other hand, soundscape researchers focus on data on individuals' responses to the acoustic environment [45]. Aletta et al., (2016) propose four main methods for soundscape research: sound walks, laboratory experiments, narrative interviews and behavioural observations [47]. These four methods are mainly related to five data collection instruments: questionnaires, semantic scales, interview protocols, physiological measures and observation protocols [47].

In recent years, with the development of information technology, mapping soundscapes have received increasing attention and numerous related studies have been conducted using ecological, humanistic and acoustic approaches [48-51]. ISO12913-2:2018 defines a sound walk as "a method of walking in an area, with emphasis on listening to the acoustic environment" [52]. Butler (2006) describes soundwalking as a way of practicing cultural geography [53], other researchers have also used soundwalking as a method of studying soundscapes [54-56].

\subsection{Soundscape Perception Assessment in Urban Parks}

The sound characteristics of urban parks are important in terms of the soundscape quality of the urban environment [57]. Urban parks are considered to be very important public spaces in a sustainable urban environment and they provide places for urban dwellers to improve their physical and mental health [11,21], many researchers regard urban parks as public spaces with restorative effects $[18,58,59]$. Noise pollution has been identified as one of the most important contributors to environmental stressors [60]. Nevertheless, the function of urban parks to improve the soundscape of the urban environment through noise reduction may be limited by their size and location [61].

The main focus of many previous studies has been on mechanical methods of reducing negative sounds in cities by reducing noise and specific decibel levels [62,63]. However, recent studies have shown that soundscape perception is not specifically associated with decibel levels, but rather with the type of soundscape, individual preference, individual sensitivity and soundscape related demographics [64-66]. For example, natural sounds such as birdsong, stream sound and wind blowing leaves sound have been shown to be positively beneficial $[43,44]$. The sound of road traffic has proven to be a negative one [67-69]. However, in terms of soundscape perception and preference, there are complex interactions between natural sounds and noise that have positive benefits. For example, people can perceive noisy environments more effectively if birdsong is added, thereby masking the noise [65]. 
Furthermore, there is an interdependent relationship between sound and visual stimuli. For example, Viollon et al., (2020) found that the more urbanised the visual environment, the more negative sounds people perceive. However this finding does depend on the type of sound heard [70]. In addition, researchers are increasingly concerned about the influence of demographic factors and behavioural aspects on the perception of outdoor soundscapes $[69,71,72]$. Age and gender have been shown to influence the perception of soundscapes [66,73-75], cultural background can also influence perceptions and assessments of the environment [76-78]. Other scholars have analysed the degree to which soundscapes are perceived by various ethnic groups. For example, in semi-structured interviews with Portuguese participants living in rural areas, Pereira et al. reveal that the sound of birdsong brings a sense of pleasure to Portuguese people [79]. Modelmog et al. interviewed farmers' wives in Amerland, Germany, about their relationship with nature and found that participants associated listening to birdsong with a positive emotional state [80]. In a series of semi-structured interviews, Ratcliffffe et al. found that the British public commonly associated the sounds of nature (e.g., water, wind and birdsong) with perceived restorative experiences (e.g., pleasure, relaxation and escape) [81]. In a qualitative study by Cerwén et al. stated that Swedish patients recovering from stress regarded the sounds of nature in a healing garden as a source of pleasure, relaxation and recovery [82]. Specifically, previous studies have focused on residential areas, commercial pedestrian streets, railway station waiting halls and urban forests, and have examined separately the effects of a number of personal factors (race, gender, age, education, occupation, social status, income, local resident status, frequency of visits, length of stay, grouping, purpose of visit, length of stay, etc.) on noise disturbance, subjective loudness, acoustic comfort, sound preference or other soundscape experiences [44,69,72,83-88].

Furthermore, in studies exploring the influence of personal attributes on the perception of urban park soundscapes, the findings have not been consistent. Several studies have found that socio-demographic information is not a significant factor in the overall soundscape preference of urban parks $[69,83]$. While the results of other researchers' experiments showed a significant effect $[44,89]$. One possible reason for these inconsistent results could be the vague definition of particular soundscapes and the correlation with people's demographics in the statistical analysis $[44,69,72,85]$.

However, comprehensive research on whether soundscapes can have stress relieving effects on urban parks and which soundscapes are important factors for restorative soundscapes (if they have positive effects) are missing. Most studies have chosen not to consider or to consider only a few important factors in the assessment of soundscapes in urban parks [7,90-92].

Therefore, this study aims to investigate whether urban park environments can relieve stress, the differences in the stress relieving effects of different urban park environments and whether soundscapes have any effect on relieving stress in urban parks, and to investigate in depth which soundscapes are important factors in restorative soundscapes (if any positive effects), with a view to informing the design of restorative soundscapes in urban parks.

\section{Materials and Methods}

\subsection{Study Areas}

Similar to other central cities in China, Fuzhou has an urban population of close to 10 million permanent dwellers, which is representative of most urban characteristics in China. Located in the heart of Fuzhou City, China, Fuzhou West Lake Park is the best preserved urban park in Fuzhou with a history of over 1700 years [93]. The whole park is in the traditional Chinese classical garden style, and is representative of the characteristics of certain Fuzhou urban parks. Fuzhou West Lake Park is located at the northern edge of the subtropical zone, with a mild subtropical monsoon climate and abundant rainfall. The soil is predominantly red loam, which is strongly acidic. The park is rich in botanical resources, with planted and natural forests, and some natural shrubland. Fuzhou West Lake Park now covers an area of 76.28 ha, including 27.84 ha of land and 48.44 ha of 
water. The selection and application of aquatic plants in the park are mostly flowering and leafy water-bearing plants, with less use of floating leaves, floating and submerged plants, mainly ornamental plants. It connects the Kaihua, Xieping and Yaojiao islands in the West Lake into a complete landscape by means of the Liuti Bridge, the Buyun Bridge, the Yudai Bridge and the Feihong Bridge. The shoreline of Fuzhou West Lake Park is about $8.3 \mathrm{~km}$ long, and the park is now fully equipped with a walkway around the lake, with an outer walkway of about $4.3 \mathrm{~km}$ and an inner walkway of about $4.4 \mathrm{~km}$, including a wooden walkway of about $2.6 \mathrm{~km}$, which well meets the needs of people who are close to the water and near the water. Being located in the centre of Fuzhou City, the surrounding area is easily accessible and therefore has a high number of visitors. Since the free opening of Fuzhou West Lake Park, the number of visitors has risen rapidly from 600,000 per year to over 2 million per year, with daily visits reaching several thousand people. Therefore, it is consistent with the site selection of the sample urban park environments in this study, as shown in Figure 2.
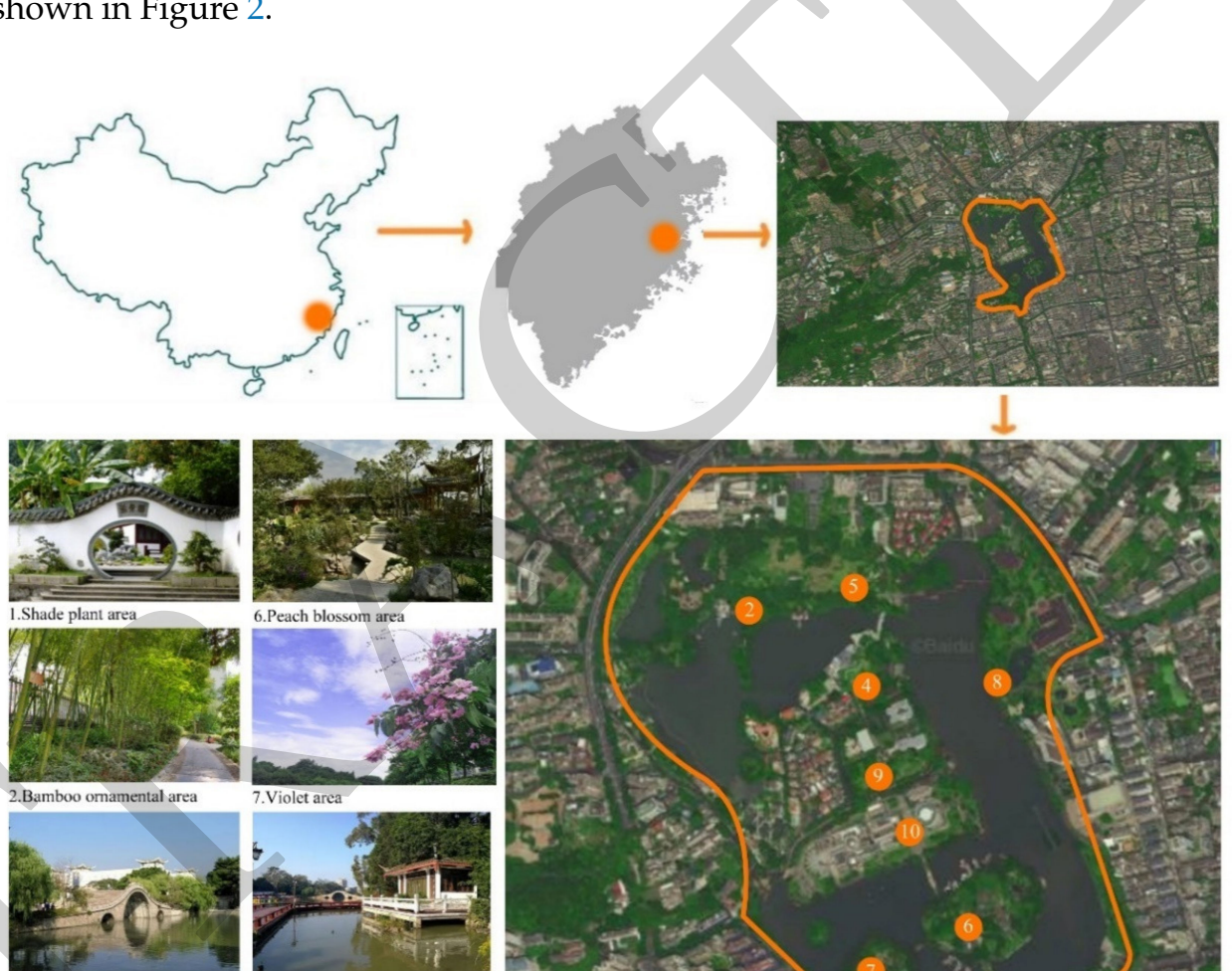

3.Archbridge area

8. Water trail area
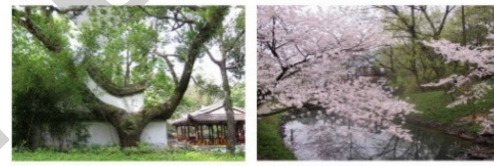

4.Ancient banyan area
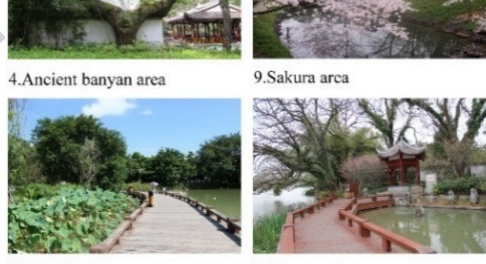

9.Sakura arca
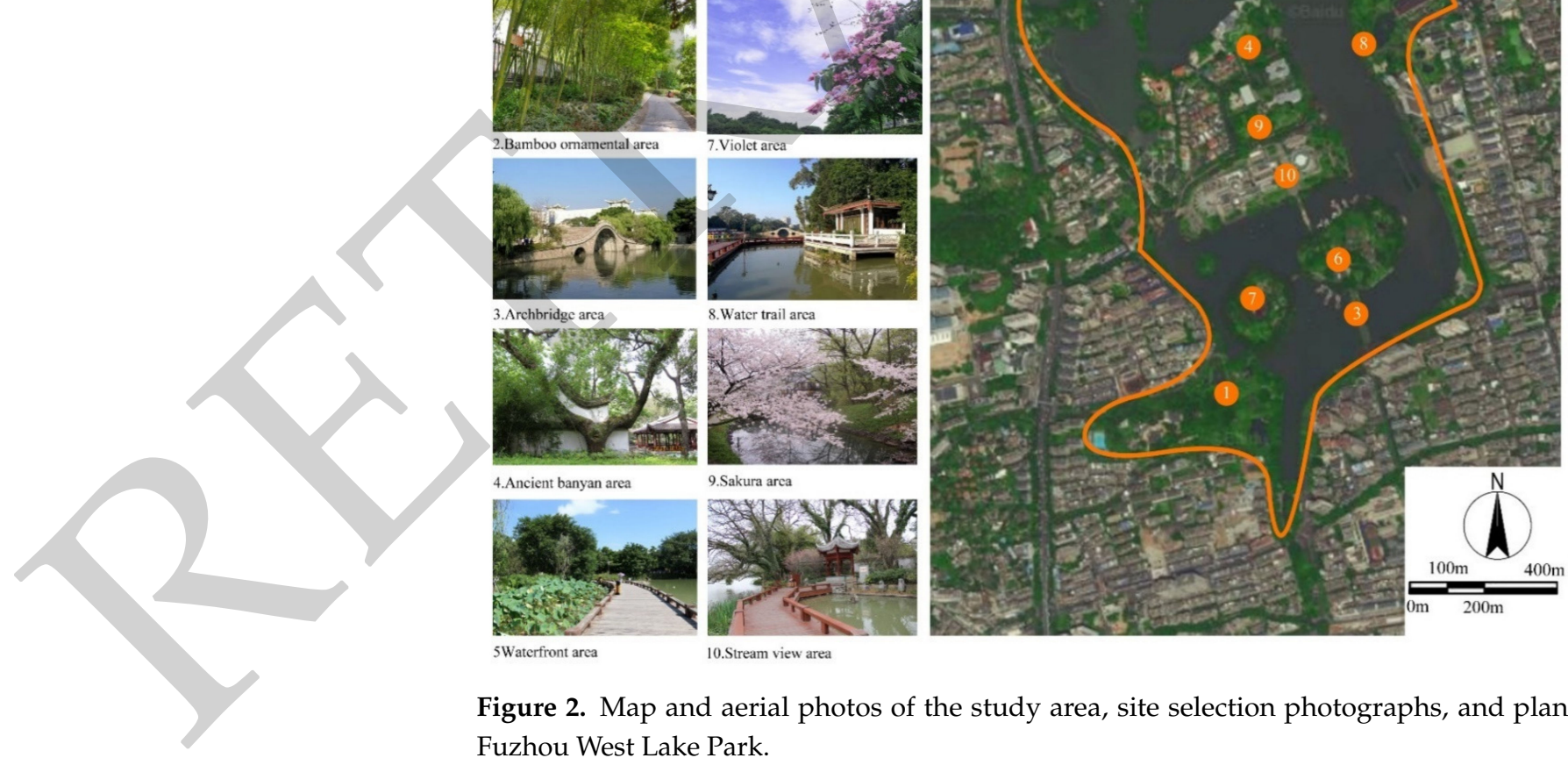

Figure 2. Map and aerial photos of the study area, site selection photographs, and plan view of Fuzhou West Lake Park.

To meet the richness of the soundscape and visual perception elements of the sample sites, 20 different urban park environments were selected around the main touring routes of Fuzhou West Lake Park through field research. In this study, two experts in landscape architecture were invited to rate 20 videos of urban park environments filmed according to the representativeness of the sample sites, the richness of the sample site soundscape types (whether they included multiple sound types of natural, human-based sounds, 
mechanical and cultural sounds), and to test the reliability of the ratings using Cohen's Kappa consistency test. The Cohen's Kappa coefficient was 0.795 , which is above the acceptable level of agreement [94]. The top 10 scoring urban park environments were selected as the study sample sites, covering the main specialised parks and major attractions across the park, with highly representative characteristics of urban park environments. This study uses Leq(A) as a measure of noise, which is a measure of undulating or intermittent noise that can be evaluated using a time-averaged approach to noise energy. Leq(A) is therefore applicable as a measure of noise in this study. leq(A) is calculated as shown in Equation (1), where $T$ represents the total measurement period; $L_{A i}$ represents the $\mathrm{i}$-th A-weighted sound level in $\mathrm{dB}$; and $\tau_{i}$ represents the sampling interval $\mathrm{S}$.

$$
L_{e q(A)}=10 \lg \left[\frac{1}{T} \sum_{i=1}^{n} 10^{0.1 L_{A i}} \tau_{i}\right]
$$

Table 1 shows the Location, Environment characteristic and Leq(A) of the 10 urban park environmental sample sites.

Table 1. Environmental characteristics of the sample sites.

\begin{tabular}{|c|c|c|c|}
\hline Sample Site No. & Location & Environment Characteristic & $\begin{array}{c}\text { Leq(A) } \\
\text { dBA }\end{array}$ \\
\hline S1 & Shade plant area & $\begin{array}{c}\text { Wooded landscape with rich } \\
\text { vegetation }\end{array}$ & 36 \\
\hline S2 & Bamboo ornamental area & $\begin{array}{c}\text { Bamboo forest, recreational } \\
\text { trails }\end{array}$ & 42 \\
\hline S3 & Archbridge area & $\begin{array}{c}\text { More hard paving and a high } \\
\text { degree of artificiality }\end{array}$ & 41 \\
\hline S4 & Ancient banyan area & $\begin{array}{c}\text { thousand-year-old banyan } \\
\text { trees }\end{array}$ & 34 \\
\hline S5 & & $\begin{array}{c}\text { Vaterside recreation area with } \\
\text { open calm waters and } \\
\text { thousand-year-old banyan } \\
\text { trees }\end{array}$ & 51 \\
\hline S6 & Peach blossom area & $\begin{array}{l}\text { Slightly undulating terrain } \\
\text { with a temple on the side } \\
\text { Dominated by different }\end{array}$ & 42 \\
\hline & Violet area & $\begin{array}{c}\text { varieties of yew, some with } \\
\text { flowering }\end{array}$ & 36 \\
\hline & Nater trail area & $\begin{array}{c}\text { Plunge landscaping with open } \\
\text { views }\end{array}$ & 53 \\
\hline & Sakura area & $\begin{array}{l}\text { Sakura, wooden paths, } \\
\text { wooded landscape }\end{array}$ & 45 \\
\hline S1 & Stream area & $\begin{array}{c}\text { A more natural view of the } \\
\text { stream }\end{array}$ & 56 \\
\hline
\end{tabular}

\subsection{Audiovisual Data Acquisition and Synthesis}

With regard to assessment methods for urban environments, most previous soundscape studies have been conducted in situ, involving processes such as sound walks and narrative interviews to ensure full ecological validity [64,95]. Recent research has applied video technology to many acoustic environment assessment tests, allowing the participants to have more immersive experiences in a limited laboratory environment [96-98]. Various studies have suggested the use of audiovisual methods to achieve close simulation of real active urban spaces and have validated the application of video technology to assess the effectiveness of simulated soundscapes in indoor environments [70,99-103]. Several studies have shown that the perception of audiovisual stimuli exposed to the indoor environment shows a sufficiently agreement with the actual natural environment $[104,105]$. Research 
on headphones and loudspeaker-based video systems have shown that the use of video technology can achieve similar effects to the real environment for sound or environmentrelated attributes [99]. Thus, although video technology cannot fully simulate the various physical senses such as smell and light, it can be fully applied to the evaluation of the audiovisual perception of the urban environment.

The site environment is full of distractions and to ensure that it is not influenced by extraneous factors such as human activity, this study was conducted by recording video outdoors and conducting the study indoors. In this study, a Sony NEX-VG30EH HD digital video camera was used to record video and a Sony PCM-D100 digital audio recorder was used to record sound, and a location in the sample area was selected as an open space. The recording is done on a tripod set at a height of $1.5 \mathrm{~m}$, with the microphone facing perpendicular to the wind direction to minimise interference, and with video and sound recorded simultaneously for a single recording time of at least $3 \mathrm{~min}$. In order to avoid climatic disturbances, a clear and windless day was selected for the video recording and the sound pressure level was measured using an AWA 5636 sound level meter while recording the sound. Three monitoring points were set up in each sample plot, and each monitoring point was measured three times, each time for 3 min continuously. The average value of Leq(A) for the three monitoring points in the same plot was calculated as shown in Table 1.

This study used Adobe Premiere Pro software to edit recorded video and audio at a size of 1024 pixels $\times 768$ pixels for $20 \mathrm{~s}$ each, exporting 10 videos with sound, followed by 10 videos without sound in a silent track, for a total of 20 video materials for the experiment.

\subsection{Participants}

The aim of this study is to determine the effects of soundscapes on relieving stress in urban parks based on various physiological indexes. Urban parks are the primary setting for recreation for resters (people) and therefore the subjects involved in this study are people. During the COVID-19 pandemic, university students were mainly studying online, and the stress of studying made them a larger group affected by stress [106,107] and suitable as participants in this study. The study shows the breadth and scientificity of school students as participants in the experiment [108], so this study invited 35 eligible university students from China XX University to participate in the experiment as volunteers. Due to problems such as sensors falling off and lack of power during the experiment, the final sample was 30 participants, 14 males and 16 females, with an average age of $(24.1 \pm 2.8)$ years, including 5 undergraduates, 21 masters students and $4 \mathrm{PhD}$ students. To ensure the validity of the experiment, all participants were blinded to the content of this experiment. All participants in the experiment have standard level of vision and hearing and all had submitted a certificate of good health.

\subsection{Soundscapes Composition and Evaluation}

In this study, eleven soundscapes were selected through field research, divided into natural sounds (birdsong, insect sound, cicada sound, stream sound, wind blowing leaves sound), human-based sounds (footstep sound, conversation sound and children playing sound) and mechanical sounds (traffic sound and bell). Three of these soundscapes (stream sound, bell and birdsong) have been shown to be restorative soundscape perceptions [92]. As shown in Figure 3, this study used the soundscape perception assessment questionnaire to quantify the degree of soundscape perception, using a seven-point Likert scale with the question "What degree do you hear the following sounds in the current environment?" $(1=$ not at all, $2=$ very little, $3=$ a little, $4=$ somewhat, $5=$ a fair bit, $6=$ very much, $7=$ completely) 


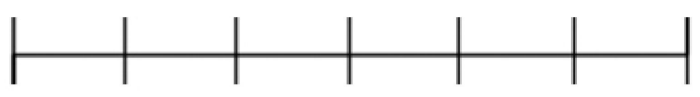

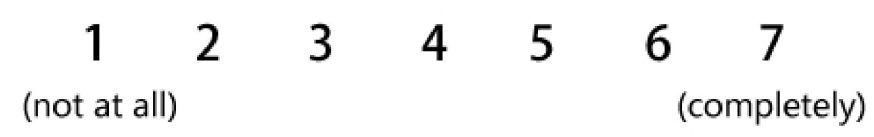

Figure 3. The seven-point scale for degree of soundscape perception.

\subsection{Physiological Indexes}

Exploring the effects of soundscapes on relieving stress is the focus of this study. Restorative indexes of relieving stress include both psychological and physiological aspects, and this study focuses on measuring the effects of soundscapes on relieving stress through physiological indexes. In previous studies, clear evidence that soundscapes can relieve stress came from a physiological study that reported that natural sounds can lower skin conductance level (SCL) faster than traffic noise [25]. Another study explored people's physiological responses to 18 sound bites and found that participants' heart rate (HR) decreased significantly after exposure to all soundscapes, although to varying degrees [109]. While some physiological indexes recovered significantly after soundscape exposure, others were not affected at all. For example, although Alvarsson et al. demonstrated a restorative effect of natural sound on skin conductance level (SCL), they failed to reveal a significant effect on recovery of heart rate variability (LF/HF) [25]. Another study, also using skin conductance level (SCL) as a measure of stress, compared physiological recovery after exposure to birdsong and traffic sounds and found no significant difference between them in terms of relieving stress [110]. Therefore, this study measured the effects of soundscapes on relieving stress in urban parks by using three physiological indexes of skin conductance level (SCL), heart rate (HR) and heart rate variability (LF/HF), which have been shown to be effective measures of relieving stress in previous studies [111-113].

As shown in Figure 4, this study uses ErgoLAB's smart wearable human factors physiological recorder (Wearable wrist sensor, Wearable chest sensor, Wearable finger sensor, Wearable ear sensor). The participants' skin conductance level (SCL), heart rate $(\mathrm{HR})$ and heart rate variability (LF/HF) signal sequences were collected using the ErgoLAB data platform, with EDA sensors for monitoring electrodermal activity and PPG sensors for monitoring heart rate and heart rate variability. ErgoLAB has been shown to be a valid tool for physiological state data collection.

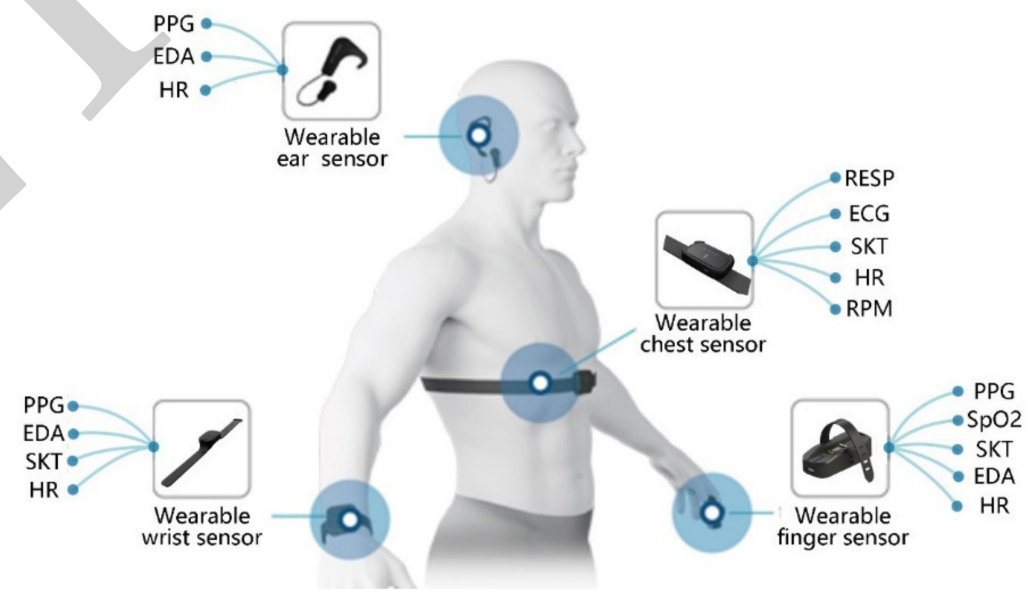

Figure 4. Display diagram of the smart wearable human factors physiology recorder.

\subsubsection{Skin Conductance Level}

Electrodermal activity is an electrical phenomenon that occurs in response to changes in the function of the skin's sweat glands, reflects sympathetic activity and is an index 
of emotional and cognitive load [114]. The increased secretion of sweat glands causes an increase in electrical conductivity and a rise in skin conductivity level. Conversely, mental relaxation leads to a decrease in skin conductivity level. Skin conductance level is the absolute value of skin conductance between 2 points and is significantly influenced by individual sweat gland activity and is the most commonly used index of skin electrical activity [22,25]. In order to reduce the test error, the skin conductance level of each participant in the calm state was taken as the baseline $\left(\mathrm{SCL}_{\mathrm{b}}\right)$, and the difference between the skin conductance levels $\left(\mathrm{SCL}_{\mathrm{S}}\right)$ of the participant under different stimuli and the baseline was divided to obtain the skin conductance level response rate $\left(\mathrm{SCL}_{\mathrm{r}}\right)$ as the study index, i.e., the Equation (2):

$$
\mathrm{SCL}_{r}=\left(\mathrm{SCL}_{s}-\mathrm{SCL}_{b}\right) / \mathrm{SCL}_{s}
$$

\subsubsection{Heart Rate and Heart Rate Variability}

Heart rate is the number of heartbeats per minute in a normal person in a quiet state, i.e., the frequency of heart contractions. Changes in heart rate reflect the level of activity of the sympathetic and parasympathetic nervous systems. When an individual is at rest or relaxed, the parasympathetic nervous system strengthens and the heart rate slows down. When an individual is in a state of tension or stress, the sympathetic nervous system becomes more excited, the parasympathetic nervous system becomes less excited and the heart rate increases. Heart rate variability is a time series consisting of the interval between successive $\mathrm{R}$ waves and the next $\mathrm{R}$ wave, and refers to the variation in the difference from one heartbeat cycle to the next, i.e., the speed of the heartbeat [115]. This study focuses on the ratio of low frequency heart rate variability (LF) to high frequency heart rate variability (HF), or LF/HF, which mainly reflects sympathetic activity and also shows the balance between the sympathetic and parasympathetic nervous systems.

\subsection{Experimental Procedure}

The experimental procedure used in this study is based on the design of Shan Shu et al. to assess the stress relieving effects of soundscapes in urban spaces [92], which has been validated and endorsed by other scholars [116]. In this study, silent video tests were also used to assess the effect of soundscapes in audible video on relieving stress in urban parks. Therefore, the experimental site for this study was chosen to be conducted in a standard fully anechoic chamber.

This study also used ambient noise from an urban park as a control stimulus, which was recorded in Fuzhou West Lake Park on a normal weekend. The ambient noise in an urban park consists of a variety of sound sources, including people talking, sounds of activity, music and some noise from distant traffic, and a $20 \mathrm{~s}$ sample from each recording was extracted for audio reproduction [92]. In order to simulate realistic urban park ambient noise, the noise was set at $50 \mathrm{dBA}$ based on general measurements from previous studies [117], and a signal to noise(S/N) of $5 \mathrm{~dB}$ was applied since it was reported as the most restorative $\mathrm{S} / \mathrm{N}$ in a preliminary test [118].

There was only one operator and one participant in the laboratory, and the participant wore headphones (AKG K271MKII) to watch the video in order to avoid extraneous interference as much as possible. As shown in Figure 5, the experimental procedure consisted of four phases. Phase 1 is the preparation and introduction phase, where the participant is explained the experimental procedure and the use of the apparatus by the operator. Phase 2 is a 3-min baseline acquisition phase where the participant is fitted with the EDA sensor by the operator, asked to remain silent and relaxed during the acquisition, and then fitted with the PPG sensor after the acquisition. Phase 3 is the data acquisition phase, during which the participant is asked to remain as still as possible, wearing a headset in a seated position for video watching. The phase is divided into three parts: (1) a 20 s ambient noise; (2) a 20 s experimental video in random order; (3) a 1 min break, after which the sequence resumes and is repeated nine times. To minimise bias, the order of ambient noise and experimental video playing was randomised each time. Phase 4 
was a soundscape perception evaluation phase in which participant evaluated the five audio videos that were played at the time. Each subject completed the experiment within 2 days to reduce fatigue and audiovisual memory. The experimental tests were divided into 2 groups of five audio and five silent videos from each of the five sample sites, with one group of tests conducted for approximately $30 \mathrm{~min}$ each time, for a total of $60 \mathrm{~min}$.

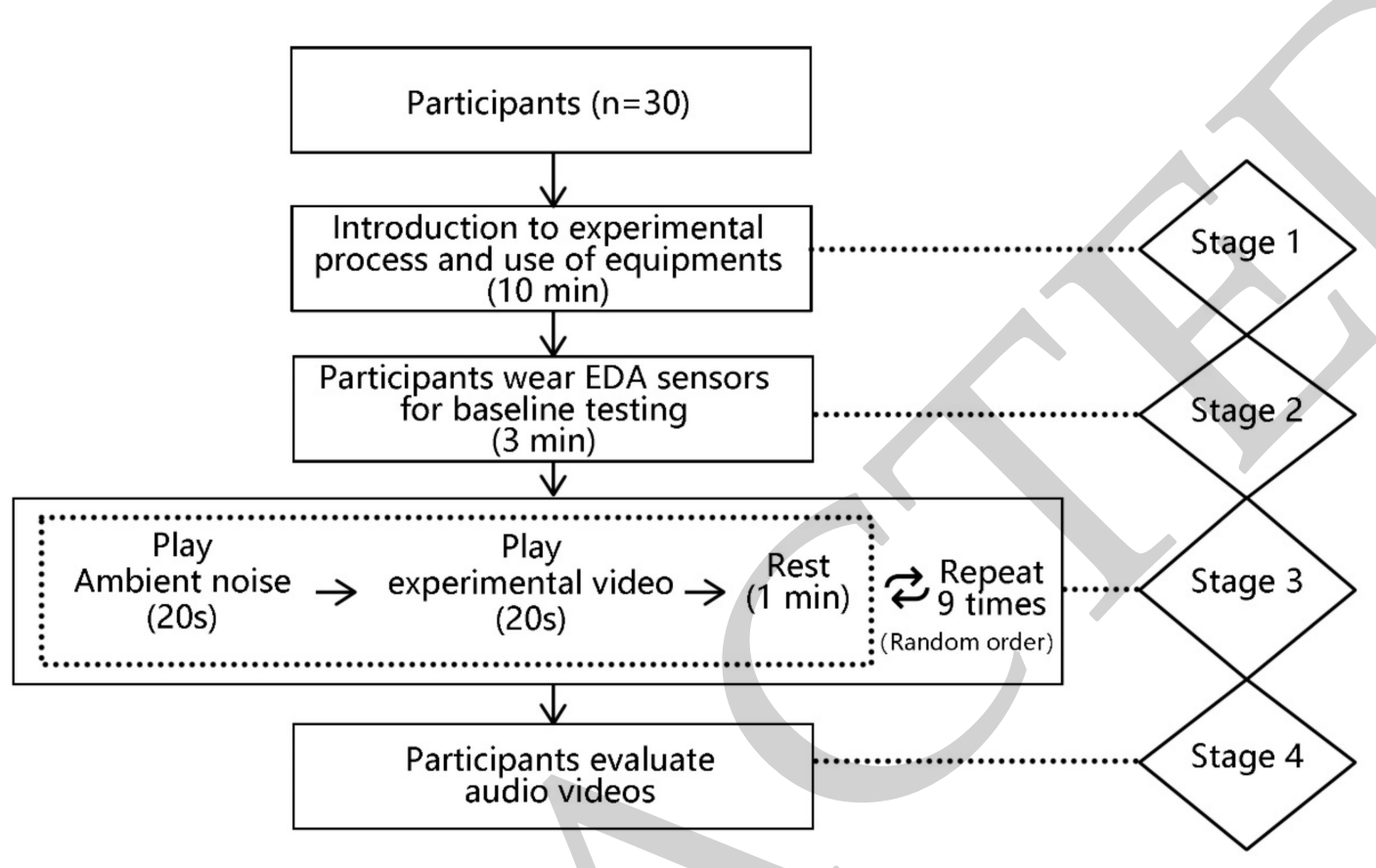

Figure 5. The experimental process.

\subsection{Data Processing}

We defined the stress relieving effects of soundscapes as the stress relieving effects of adding a soundscape to an urban park. The stress relieving effect of the combined audiovisual test $\left(R_{a-v}\right)$ minus the stress relieving effect of the silent test $\left(R_{v}\right)$ is the stress relieving effect of the soundscape $\Delta R$ (the skin conductance level response rate for the soundscape is $\triangle S L C_{r}$, the heart rate for a soundscape is $\Delta H R$, and the heart rate variability for a soundscape is $\Delta \mathrm{LF} / \mathrm{HF})($ Equation (3)):

$$
\Delta \mathrm{R}=\mathrm{R}_{\mathrm{a}-\mathrm{v}}-\mathrm{R}_{v}
$$

The physiological indexes were analysed and exported using the Ergo LAB data platform and the data were processed using SPSS 24.0 software. This study uses the Wilcoxon test to analyse the effects of urban park environments on relieving stress and the effects of soundscapes on relieving stress in an urban park, uses median analysis of the stress relieving effects of different urban park environments, and identifies important factors in restorative soundscapes through regression analysis (if they have any positive effect).

\section{Results}

\subsection{Sample Site Soundscape Characteristics}

As shown in Table 2, the perception of insect sound, birdsong and cicada sound in sample site S1 was high. Cicada and insect sounds were perceived most highly in sample site S2, followed by birdsong. The degree of soundscape perception in sample site S3 is similar to that in sample site S2, with higher perception of cicada sound, insect sound and birdsong. The highest degree of birdsong perception was found in sample site S4, followed by insect sound and cicada sound. Soundscape perception in sample site S5 is dominated by stream sound and birdsong, with a high perception of conversation sound and children 
playing sound. The perception of birdsong, insect sound and cicada sound was higher in sample site S6, as was the perception of bell. The highest degree of birdsong perception was found in sample site S7, followed by insect sound and cicada sound. Sample site S8 is dominated by stream sound, with other natural sounds perceived as weak. The highest degree of insect sound perception was found in sample site S9, followed by cicada sound and birdsong. Sample site S10 is dominated by stream sound, followed by insect sound and cicada sound.

Table 2. The degree of soundscape perception of each sample site.

\begin{tabular}{|c|c|c|c|c|c|c|c|c|c|c|}
\hline Soundscape & S1 & S2 & S3 & S4 & S5 & S6 & S7 & S8 & S9 & S10 \\
\hline $\begin{array}{l}\text { Stream } \\
\text { sound }\end{array}$ & 1.200 & 1.067 & 1.167 & 1.167 & 5.700 & 1.100 & $3 .($ & 6.500 & 1.200 & 6.800 \\
\hline Birdsong & 5.033 & 4.633 & 4.633 & 5.967 & 5.000 & 5.533 & 6.06 & 3.067 & 4.533 & 2.933 \\
\hline $\begin{array}{l}\text { Insect } \\
\text { sound }\end{array}$ & 5.400 & 5.800 & 5.000 & 4.033 & 3.600 & 5.000 & 4.967 & 2.767 & 5.833 & 4.033 \\
\hline $\begin{array}{l}\text { Cicada } \\
\text { sound } \\
\text { Wind }\end{array}$ & 4.900 & 6.167 & 5.500 & 3.533 & 2.933 & 4.533 & 4.733 & 2.233 & 4.700 & 3.767 \\
\hline $\begin{array}{c}\text { blowing } \\
\text { leaves } \\
\text { sound }\end{array}$ & 2.500 & 2.900 & 2.933 & 2.033 & 2.300 & 2.267 & 3.500 & 2.033 & 2.767 & 2.267 \\
\hline $\begin{array}{l}\text { Wind } \\
\text { sound }\end{array}$ & 2.100 & 2.667 & 2.500 & 1.900 & 2.033 & 2.033 & 3.267 & 1.700 & 2.233 & 1.933 \\
\hline $\begin{array}{l}\text { Footstep } \\
\text { sound }\end{array}$ & 1.567 & 1.067 & 1.367 & 1.400 & 1.933 & 1.100 & 1.500 & 1.067 & 1.167 & 1.033 \\
\hline $\begin{array}{l}\text { Conversation } \\
\text { sound }\end{array}$ & 1.033 & 1.133 & 1.300 & 1.467 & 3.467 & 1.200 & 1.033 & 1.133 & 1.100 & 1.033 \\
\hline $\begin{array}{l}\text { Children } \\
\text { playing } \\
\text { sound }\end{array}$ & 1.033 & 1.133 & 1.033 & 1.767 & 3.233 & 1.067 & 1.033 & 1.033 & 1.100 & 1.033 \\
\hline $\begin{array}{l}\text { Traffic } \\
\text { sound }\end{array}$ & 1.233 & 1.133 & 1.533 & 1.433 & 1.067 & 1.300 & 1.033 & 1.133 & 1.300 & 1.033 \\
\hline Bell & 1.033 & 1.000 & 1.000 & 1.200 & 1.033 & 4.867 & 1.000 & 1.033 & 1.033 & 1.000 \\
\hline
\end{tabular}

4.2. Differences in Physiological Indexes between the Ambient Noise and Experimental Video Phases of the Different Urban Park Environments

This study uses the Wilcoxon test to compare the differences in three physiological indexes between the ambient noise phase and the experimental video phase of the different urban park environments. As can be seen from Table 3, the physiological indexes of SCL $\mathrm{L}_{\mathrm{r}}$ decreased in the ten urban park environments during the experimental video phase, with significant reductions $(p<0.01)$ in sample site S2, S4, S7 and S10. The physiological indexes of HR were reduced in the experimental video phase, with significant reductions in sample sites S7 and S10. Physiological indexes of LF/HF decreased during the experimental video phase, with significant $(p<0.05)$ decreases in sample sites S1, S4, S6, S7, S8, S9 and S10 $(p<0.05)$ and a highly significant decrease in sample site $\mathrm{S} 7(p<0.001)$. This suggests that participants' stress can be recovered to a certain degree in the urban park environments, but there are differences in the degree of recovery from one urban park environment to another. 
Table 3. Differences in physiological indexes between the ambient noise phase and the experimental video phase.

\begin{tabular}{|c|c|c|c|c|c|c|c|}
\hline \multirow{2}{*}{$\begin{array}{c}\text { Sample } \\
\text { Site }\end{array}$} & \multirow{2}{*}{$\begin{array}{l}\text { Physiological } \\
\text { Index }\end{array}$} & \multicolumn{2}{|c|}{ Ambient Noise } & \multicolumn{2}{|c|}{ Experimental Video } & \multirow{2}{*}{$\begin{array}{c}\text { Mean } \\
\text { Difference }\end{array}$} & \multirow{2}{*}{$Z$} \\
\hline & & Mean & SD & Mean & SD & & \\
\hline \multirow{3}{*}{ S1 } & $\mathrm{SCL}_{\mathrm{r}}$ & 0.091 & 0.315 & 0.072 & 0.324 & -0.019 & -0.562 \\
\hline & HR & 84.767 & 5.788 & 84.200 & 6.354 & -0.567 & -0.629 \\
\hline & $\mathrm{LF} / \mathrm{HF}$ & 0.523 & 0.225 & 0.465 & 0.229 & -0.057 & $-2.407 *$ \\
\hline \multirow{3}{*}{ S2 } & $\mathrm{SCL}_{\mathrm{r}}$ & 0.214 & 0.338 & 0.190 & 0.333 & -0.024 & $-2.016^{*}$ \\
\hline & HR & 86.100 & 5.991 & 85.467 & 5.367 & -0.633 & -0.638 \\
\hline & $\mathrm{LF} / \mathrm{HF}$ & 0.470 & 0.252 & 0.407 & 0.188 & -0.063 & -1.594 \\
\hline \multirow{3}{*}{ S3 } & $\mathrm{SCL}_{\mathrm{r}}$ & 0.092 & 0.310 & 0.084 & 0.314 & -0.008 & -0.453 \\
\hline & $\mathrm{HR}$ & 86.333 & 4.978 & 86.000 & 6.253 & -0.333 & -0.038 \\
\hline & $\mathrm{LF} / \mathrm{HF}$ & 0.581 & 0.325 & 0.558 & 0.257 & -0.023 & -0.854 \\
\hline \multirow{3}{*}{ S4 } & $\mathrm{SCL}_{\mathrm{r}}$ & 0.106 & 0.384 & 0.066 & 0.364 & -0.040 & $-2.715^{* *}$ \\
\hline & $\mathrm{HR}$ & 86.033 & 6. 311 & 85.133 & 6.394 & -0.900 & -1.107 \\
\hline & $\mathrm{LF} / \mathrm{HF}$ & 0.603 & 0.395 & 0.530 & 0.348 & -0.073 & $-2.458 *$ \\
\hline \multirow{3}{*}{ S5 } & $\mathrm{SCL}_{\mathrm{r}}$ & 0.084 & 0.346 & 0.063 & 0.364 & -0.021 & -0.984 \\
\hline & HR & 85.033 & 6.212 & 84.300 & 4.735 & -0.733 & -0.820 \\
\hline & $\mathrm{LF} / \mathrm{HF}$ & 0.498 & 0.262 & 0.439 & 0.204 & -0.059 & -1.491 \\
\hline \multirow{3}{*}{ S6 } & $\mathrm{SCL}_{\mathrm{r}}$ & 0.133 & 0.314 & 0.078 & 0.306 & -0.055 & -1.224 \\
\hline & $\mathrm{HR}$ & 86.233 & 5.097 & 85.267 & 5.681 & -0.967 & -1.110 \\
\hline & $\mathrm{LF} / \mathrm{HF}$ & 0.636 & 0.374 & 0.544 & 0.290 & -0.092 & $-2.047 *$ \\
\hline \multirow{3}{*}{ S7 } & $\mathrm{SCL}_{\mathrm{r}}$ & 0.163 & 0.330 & 0.054 & 0.363 & -0.109 & $-2.808^{* *}$ \\
\hline & $\mathrm{HR}$ & 87.133 & 5.204 & 84.233 & 5.056 & -2.900 & $-2.340 *$ \\
\hline & $\mathrm{LF} / \mathrm{HF}$ & 0.513 & 0.227 & 0.372 & 0.178 & -0.141 & $-4.268^{* * *}$ \\
\hline \multirow{3}{*}{ S8 } & $\mathrm{SCL}_{\mathrm{r}}$ & 0.195 & 0.322 & 0.123 & 0.345 & -0.072 & -1.707 \\
\hline & $\mathrm{HR}$ & 85.633 & 4.414 & 84.233 & 5.335 & -1.400 & -1.686 \\
\hline & $\mathrm{LF} / \mathrm{HF}$ & 0.595 & 0.321 & 0.477 & 0.252 & -0.118 & $-2.480 *$ \\
\hline \multirow{3}{*}{ S9 } & $\mathrm{SCL}_{\mathrm{r}}$ & 0.155 & 0.322 & 0.089 & 0.391 & -0.066 & -1.502 \\
\hline & $\mathrm{HR}$ & 85.767 & 5.494 & 84.733 & 6. 438 & -1.033 & -1.292 \\
\hline & $\mathrm{LF} / \mathrm{HF}$ & 0.572 & 0.338 & 0.443 & 0.237 & -0.128 & $-2.057^{*}$ \\
\hline \multirow{3}{*}{ S10 } & $\mathrm{SCL}_{\mathrm{r}}$ & 0.235 & 0.392 & 0.111 & 0.395 & -0.124 & $-2.822^{* *}$ \\
\hline & $\mathrm{HR}$ & 85.933 & 5.285 & 84.300 & 4.872 & -1.633 & $-2.194 *$ \\
\hline & $\mathrm{LF} / \mathrm{HF}$ & 0.524 & 0.251 & 0.422 & 0.229 & -0.103 & $-2.973^{* *}$ \\
\hline
\end{tabular}

\subsection{Differences in the Stress Relieving Effects of Different Urban Park Environments}

In this study, the differences in physiological indexes between the ambient noise phase and the experimental video phase were used to express the degree of recovery, i.e., the stress relieving effects. As shown in Table 3, the difference in physiological indexes for SCLr was $\mathrm{S} 10<\mathrm{S} 7<\mathrm{S} 8<\mathrm{S} 9<\mathrm{S} 6<\mathrm{S} 4<\mathrm{S} 2<\mathrm{S} 5<\mathrm{S} 1<\mathrm{S} 3$, for $\mathrm{HR}$ was $\mathrm{S} 7<\mathrm{S} 10<\mathrm{S} 8<\mathrm{S} 9<\mathrm{S} 6<\mathrm{S} 4<$ $\mathrm{S} 5<\mathrm{S} 2<\mathrm{S} 1<\mathrm{S} 3$, and for $\mathrm{LF} / \mathrm{HF}$ was $\mathrm{S} 7<\mathrm{S} 9<\mathrm{S} 8<\mathrm{S} 10<\mathrm{S} 6<\mathrm{S} 4<\mathrm{S} 2<\mathrm{S} 5<\mathrm{S} 1<\mathrm{S} 3$. The median test found significant differences in the difference in physiological indexes for SCLr $(p=0.016<0.05)$, but not for HR and LF/HF, across the urban park environment sample sites.

\subsection{The Effects of Soundscapes on Relieving Stress in an Urban Park}

This study uses the Wilcoxon test to compare the differences in relieving stress effects between audio and silent videos and the results are shown in Table 4. Analysis of the physiological indexes of SCLr, HR and LF/HF in the participants revealed that the addition of sound resulted in significant changes in the physiological indexes of each urban park environment. In terms of the physiological indexes of SCLr, the inclusion of soundscape showed a decreasing trend in all nine urban park environments except for sample site S5, where sample sites S8 and S10 showed a significant decrease $(p<0.01)$. In terms of the physiological indexes of HR, the addition of the soundscape resulted in a decreasing trend in all nine urban park environments, except for sample site S5, where only sample site 
S7 showed a significant decrease $(p<0.05)$. In terms of physiological indexes of LF/HF, all nine urban park environments showed a decreasing trend after the addition of the soundscape, except for sample site S5, where only sample site S7 showed a significant decrease $(p<0.01)$. This suggests that relieving stress effects can be improved to a certain degree in urban park environments, with the exception of sample urban park environment S5, which did not improve relieving stress effects. This result may be due to the fact that in the urban park environment sample site S5, which contains open calm water, the silent video in sample site S5 itself has relieving stress effects on the participants [7].

Table 4. Differences in relieving stress effects between silent video and audio video.

\begin{tabular}{|c|c|c|c|c|c|c|c|}
\hline \multirow{2}{*}{ Sample Site } & \multirow{2}{*}{$\begin{array}{l}\text { Physiological } \\
\text { Index }\end{array}$} & \multicolumn{2}{|c|}{ Audio Video } & \multicolumn{2}{|c|}{ Silent Video } & \multirow{2}{*}{$\begin{array}{c}\text { Mean } \\
\text { Difference }\end{array}$} & \\
\hline & & Mean & SD & Mean & SD & & \\
\hline \multirow{3}{*}{ S1 } & $\mathrm{SCL}_{\mathrm{r}}$ & -0.019 & 0.089 & -0.010 & 0.110 & -0.009 & -0.401 \\
\hline & HR & -0.567 & 4.681 & -0.400 & 4.446 & -0.167 & -0.342 \\
\hline & $\mathrm{LF} / \mathrm{HF}$ & -0.057 & 0.166 & -0.022 & 0.091 & -0.035 & -1.018 \\
\hline \multirow{3}{*}{ S2 } & $\mathrm{SCL}_{\mathrm{r}}$ & -0.024 & 0.070 & -0.005 & 0.088 & -0.019 & -0.360 \\
\hline & HR & -0.633 & 6.133 & -0.133 & 4.953 & -0.500 & -0.082 \\
\hline & $\mathrm{LF} / \mathrm{HF}$ & -0.063 & 0.219 & -0.031 & 0.314 & -0.032 & -0.998 \\
\hline \multirow{3}{*}{ S3 } & $\mathrm{SCL}_{\mathrm{r}}$ & -0.008 & 0.065 & -0.001 & 0.224 & -0.007 & -0.381 \\
\hline & $\mathrm{HR}$ & -0.333 & 6.194 & -0.133 & 5.104 & -0.200 & -0.455 \\
\hline & $\mathrm{LF} / \mathrm{HF}$ & -0.024 & 0.239 & -0.011 & 0.251 & -0.013 & -0.072 \\
\hline \multirow{3}{*}{ S4 } & $\mathrm{SCL}_{\mathrm{r}}$ & -0.040 & 0.081 & -0.035 & 0.064 & -0.005 & -0.051 \\
\hline & $\mathrm{HR}$ & -0.900 & 3.546 & -0.500 & 3.093 & -0.400 & -0.310 \\
\hline & $\mathrm{LF} / \mathrm{HF}$ & -0.073 & 0.204 & -0.049 & 0.408 & -0.024 & -0.154 \\
\hline \multirow{3}{*}{ S5 } & $\mathrm{SCL}_{\mathrm{r}}$ & -0.021 & 0.082 & -0.034 & 0.132 & 0.013 & -0.956 \\
\hline & HR & -0.733 & 5.179 & -1.000 & 3.572 & 0.267 & -0.057 \\
\hline & $\mathrm{LF} / \mathrm{HF}$ & -0.059 & 0.311 & -0.085 & 0.124 & 0.026 & -0.195 \\
\hline \multirow{3}{*}{ S6 } & $\mathrm{SCL}_{\mathrm{r}}$ & -0.055 & 0.296 & -0.053 & 0.212 & -0.002 & -0.720 \\
\hline & $\mathrm{HR}$ & -0.967 & 4.476 & -0.133 & 5.686 & -0.833 & -0.707 \\
\hline & $\mathrm{LF} / \mathrm{HF}$ & -0.092 & 0.252 & -0.054 & 0.239 & -0.038 & -0.710 \\
\hline \multirow{3}{*}{ S7 } & $\mathrm{SCL}_{\mathrm{r}}$ & -0.109 & 0.187 & -0.054 & 0.186 & -0.055 & -1.162 \\
\hline & $\mathrm{HR}$ & -2.900 & 6.483 & -0.300 & 6.670 & -2.600 & $-2.068 *$ \\
\hline & $\mathrm{LF} / \mathrm{HF}$ & -0.141 & 0.132 & -0.027 & 0.168 & -0.114 & $-2.664^{* *}$ \\
\hline \multirow{6}{*}{ S8 } & $\mathrm{SCL}_{\mathrm{r}}$ & -0.072 & 0.383 & -0.008 & 0.341 & -0.064 & $-2.643^{* *}$ \\
\hline & HR & -1.400 & 4.854 & -0.333 & 6.583 & -1.067 & -0.779 \\
\hline & LF/HF & -0.118 & 0.253 & -0.069 & 0.313 & -0.049 & -1.059 \\
\hline & $\mathrm{SCL}_{\mathrm{r}}$ & -0.066 & 0.290 & -0.036 & 0.204 & -0.030 & -0.627 \\
\hline & HR & -1.033 & 5.933 & -0.467 & 5.008 & -0.057 & -1.018 \\
\hline & LF/HF & -0.128 & 0.352 & -0.071 & 0.227 & -0.057 & -1.018 \\
\hline \multirow{3}{*}{ S10 } & $\mathrm{SCL}_{1}$ & -0.124 & 0.247 & -0.068 & 0.249 & -0.056 & $-2.993 * *$ \\
\hline & $\mathrm{HR}$ & -1.633 & 3.605 & -0.467 & 5.476 & -1.167 & -1.141 \\
\hline & $\mathrm{LF} / \mathrm{HF}$ & -0.103 & 0.160 & -0.054 & 0.111 & -0.048 & -0.833 \\
\hline
\end{tabular}

*: $p<0.05 ; * *: p<0.01 ; * * *: p<0.001$.

\subsection{The Relationship between Soundscapes and the Relieving Stress Effects of an Urban Park}

In previous studies, a number of scholars have demonstrated agreement between virtual and laboratory-based natural experiences and in-person experiences. For example, Puyana et al. demonstrated consistent results between immersive virtual reality-based techniques and real environments used to assess environmental noise in different areas of the city [104]. Luigi et al. compared the acoustic and visual stimuli using multisensory immersive virtual reality with the real environment and found that the subjective ratings of the visual and acoustic sources in the laboratory and the real environment achieved 
agreement. Therefore, the results of the data obtained in the laboratory in this study have a reliability consistent with that of the real environment [102].

As shown in Table 5, to explore the relationship between soundscapes and the relieving stress effects of an urban park, this study used soundscape perceptions as the independent variable and $\triangle \mathrm{SCLr}, \Delta \mathrm{HR}$ and $\triangle \mathrm{LF} / \mathrm{HF}$ as the dependent variables, respectively, for statistical regression analysis using SPSS 24.0 software. For $\Delta$ SCLr, the regression model was statistically significant with a corrected $R^{2}=0.402(p<0.001)$ and the perceived degree of birdsong $(p<0.001)$, stream sound $(p<0.001)$, cicada sound $(p<0.01)$ and footstep sound ( $p=0.052)$ were significant variables in predicting $\triangle$ SCLr. The higher the perceived degree of bird, stream and cicada sounds, the lower the $\triangle \mathrm{SCLr}$ and the higher the relieving stress effects, as indicated by the standardised coefficients. The higher the perceived degree of footstep sound, the higher the $\triangle \mathrm{SCLr}$ and the lower the relieving stress effects. Importance refers to the degree of influence of the independent variable on the prediction of the dependent variable. As shown in Table 5, the importance of the influence of soundscape perceptions on $\triangle \mathrm{SCLr}$ is as follows: birdsong $>$ stream sound $>$ cicada sound $>$ footstep sound. This study was analysed by ANOVA on $\triangle H R$ and this regression model was not statistically significantly different, $p=0.066>0.05$. Therefore, the results of the regression analysis for $\Delta \mathrm{HR}$ are not presented in Table 5 for this study. For $\Delta \mathrm{LF} / \mathrm{HF}$, the model-adjusted $\mathrm{R}^{2}=0.247$ and the regression model was statistically significant $(p<0.001)$, with birdsong $(p<0.01)$, stream sound $(p<0.01)$, cicada sound $(p<0.01)$ and wind sound $(p<0.05)$ perceptions degree being significant variables in predicting $\triangle \mathrm{LF} / \mathrm{HF}$. The higher the perception of birdsong, stream sound, cicada sound and wind sound, the lower the $\triangle \mathrm{LF} / \mathrm{HF}$ and the higher the relieving stress effects, as indicated by the standardised coefficients. The importance of the effect of soundscape perceptions on $\triangle L F / H F$ is expressed as follows: birdsong $>$ cicada sound $>$ stream sound $>$ wind sound.

Table 5. Regression analysis of soundscapes and the relieving stress effects.

\begin{tabular}{|c|c|c|c|c|c|c|c|}
\hline \multirow{2}{*}{$\begin{array}{l}\text { Dependent } \\
\text { Variable }\end{array}$} & \multirow{2}{*}{$\begin{array}{l}\text { Independent } \\
\text { Variable }\end{array}$} & \multicolumn{2}{|c|}{ Standardised Coefficients } & \multirow{2}{*}{ df } & \multirow{2}{*}{$\mathbf{F}$} & \multirow{2}{*}{ Sig. } & \multirow{2}{*}{ Significance } \\
\hline & & $\beta$ & Standard Error & & & & \\
\hline \multirow{11}{*}{$\Delta \mathrm{SCLr}$} & Stream sound & -0.489 & 0.055 & 3 & 77.806 & 0.000 & 0.301 \\
\hline & Birdsong & -0.499 & 0.054 & 3 & 86.780 & 0.000 & 0.482 \\
\hline & Insect sound & -0.097 & 0.108 & 3 & 0.818 & 0.485 & 0.048 \\
\hline & Cicada sound & -0.216 & 0.102 & 3 & 4.490 & 0.004 & 0.095 \\
\hline & $\begin{array}{l}\text { Wind blowing } \\
\text { leaves sound }\end{array}$ & 0.075 & 0.129 & 2 & 0.334 & 0.716 & 0.003 \\
\hline & Wind sound & 0.035 & 0.120 & 1 & 0.084 & 0.772 & 0.002 \\
\hline & Footstep sound & 0.081 & 0.053 & 4 & 2.383 & 0.052 & 0.019 \\
\hline & $\begin{array}{l}\text { Conversation } \\
\text { sound }\end{array}$ & 0.042 & 0.110 & 2 & 0.144 & 0.866 & 0.000 \\
\hline & $\begin{array}{l}\text { Children playing } \\
\text { sound }\end{array}$ & 0.107 & 0.090 & 2 & 1.403 & 0.248 & 0.026 \\
\hline & Traffic sound & -0.044 & 0.085 & 1 & 0.270 & 0.603 & 0.003 \\
\hline & Bell & -0.079 & 0.093 & 3 & 0.729 & 0.535 & 0.023 \\
\hline \multirow{11}{*}{$\Delta \mathrm{LF} / \mathrm{HF}$} & Stream sound & -0.289 & 0.108 & 2 & 7.215 & 0.001 & 0.154 \\
\hline & Birdsong & -0.355 & 0.145 & 3 & 5.996 & 0.001 & 0.362 \\
\hline & Insect sound & 0.094 & 0.101 & 2 & 0.868 & 0.421 & 0.012 \\
\hline & Cicada sound & -0.342 & 0.163 & 4 & 4.405 & 0.002 & 0.306 \\
\hline & Wind blowing & 0.157 & 0.111 & 3 & 2.010 & 0.113 & 0.002 \\
\hline & Wind sound & -0.187 & 0.119 & 4 & 2.460 & 0.046 & 0.052 \\
\hline & Footstep sound & 0.052 & 0.099 & 2 & 0.272 & 0.762 & 0.002 \\
\hline & $\begin{array}{l}\text { Conversation } \\
\text { sound }\end{array}$ & 0.131 & 0.111 & 4 & 1.407 & 0.232 & 0.018 \\
\hline & $\begin{array}{l}\text { Children playing } \\
\text { sound }\end{array}$ & -0.180 & 0.139 & 2 & 1.691 & 0.186 & 0.077 \\
\hline & Traffic sound & -0.051 & 0.111 & 1 & 0.211 & 0.646 & 0.014 \\
\hline & Bell & 0.036 & 0.106 & 2 & 0.119 & 0.888 & 0.001 \\
\hline
\end{tabular}

\section{Discussion}

\subsection{Ten Urban Park Environments Can Provide a Certain Degree of Relieving Stress}

The Wilcoxon test for physiological indexes in the ambient noise and experimental video phases of this study found that all ten urban park environments relieved stress to a certain degree, with significant reductions in LF/HF in urban park environment sample 
sites S1, S6, S8 and S9, SCLr in sample site S2, SCLr, LF/HF in sample site S4, SCLr, LF/HF in sample sites S7 and S10. SCLr, HR, LF/HF were significantly reduced in S7 and S10. In terms of physiology, the floral environments represented by S7 had the best stress-relieving effects, while the stream environments represented by S10 had the second-best stressrelieving effects. This confirms that natural landscapes, represented by floral and stream environments, are more effective in relieving stress than urban landscapes, which even have a negative effect on relieving stress, while natural landscapes help with short-term recovery from stress or mental fatigue [60]. This is consistent with the study presented by Wang et al., (2019) that urban park environments relieve stress, increase parasympathetic activity and inhibit sympathetic activity [119]. This study validates Ulrich et al.'s (1991) theory of stress relief, which states that if the environment has certain positive factors, it will result in effective relaxation, decreased feelings of stress and positive changes in physiological responses in the individual [120].

\subsection{Differences in the Relieving Stress Effects of Ten Different Urban Park Environments}

There are the relieving stress effects of increased parasympathetic activity and decreased sympathetic activity in the ten different urban park environments used in this study, where SCLr, HR and LF/HF levels all decreased to varying degrees. The urban park environment sample sites S7, S8, S9 and S10 with good relieving stress effects have significant natural environmental characteristics, with the better relieving stress effects of sample sites S7 and S9 probably related to the high vegetation cover and high perception of birdsong, cicada sound and insect sound [81,121]. The better relieving stress effects of the sample sites S8 and S10 may be related on the one hand to the restorative benefits of the stream sound and on the other hand to the high quality of their visual landscape $[122,123]$. Sample sites S1 and S3 had poor relieving stress effects, with sample site S1 possibly being too secluded and fearful. Sample site S3 may have a high artificial component due to its. In this study, a median test revealed significant differences $(p<0.05)$ in the physiological indexes of SCLr in the ten urban park environments, but not in HR and LF/HF, probably because the experimental tests were short enough to induce large physiological changes.

\subsection{Soundscapes Have Effects on an Urban Park in Relieving Stress}

The addition of soundscapes to urban park environments, with the exception of urban park environment sample site S5, was more conducive to reducing physiological indexes of SCLr, HR and LF/HF, increasing parasympathetic activity and suppressing sympathetic activity. Possibly because sample site S5 contains large areas of calm water, the single visual stimulus of the environment itself has stress-relieving effects [122]. As the experimental video shows large areas of water, the higher recovery effect of the sound of running water can also be explained in terms of the coherence between sound and vision. This finding supports previous research reporting that coherence between auditory and visual stimuli does play some role in the stress-relieving effects of urban park environments [28]. This is similar to the findings presented by Annerstedt et al. (2013) that a virtual urban park environment with sound activates parasympathetic nervous system activity and induces physiological stress recovery, while a virtual urban park environment without sound does not differ significantly from a traffic environment [19]. This study also provides further physiological evidence that nature-related audiovisual stimuli often have better relieving stress effects than single visual stimuli [124].

\subsection{Natural Sounds Such as Birdsong and Stream Sound Are Important Factors in Restorative Soundscapes}

The positive contribution of birdsong and stream sound to the relieving stress effects in the results of this study is significant and consistent with previous studies [19,21] Birdsong has great potential to help with stress recovery, but its restorative effect can also be influenced by the type of bird. Therefore, the addition of comforting or popular birdsong may enhance the stress-relieving effect, especially in urban parks with artificial natural elements $[81,121]$. Stream sound is an important factor in the restorative benefits 
of natural space [125]. On the one hand it eliminates a certain amount of noise [126], on the other it adds a sense of tranquillity [122]. For example, listening to the stream sound in naturopathy is more likely to help people to meditate, sit and relax [127]. Appropriate inclusion of landscape elements such as fountains, streams and waterfalls in the design of urban park environments may be able to contribute to the stress-relieving effects of urban parks. In addition, the cicada sound and wind sound also have positive effects on relieving stress, but to a lesser degree. The stress-relieving effects of urban parks may be furthered by the appropriate inclusion of cicada sound and wind sound, but their effects may be influenced by factors such as volume, location of the sound source and season [127].

\subsection{Limitations of This Study}

In terms of the selection of environmental sample sites in urban parks, only 10 environmental sample sites were selected from Fuzhou West Lake Park to explore the effects of soundscapes on relieving stress in an urban park. However, influenced by factors such as different geographical locations, climatic conditions and cultural preferences, urban park environments should be more diverse and richer in soundscapes, and future research should be conducted on different types of urban parks. In addition, the seasons are a factor in landscape change in urban parks and it is valuable to carry out research on urban parks in different seasons. In terms of research participants, although school students as participants are broad and scientific, the evaluation of school students as a representative of the public has certain limitations. In future studies, the selection of evaluation samples should be increased for different recreationists to verify the results of this study more comprehensively.

In addition, this study only described information about the gender, age and education level of the participating students and did not categorise and compare the relieving stress effects of the soundscapes for more information about their socio-demographic background. Future studies could add more information about the socio-demographic background of the participants, such as whether the participants live in urban or rural areas, or whether they grew up in urban or rural areas. These factors could then be compared and analysed to see if they affect the relieving stress effects of soundscapes.

This study validates the stress-relieving effects of urban park environments through audiovisual stimuli only, and in the future, olfactory stimuli could be added, as there are also various odour exposures in real natural environments. In terms of research methodology, indexes of the autonomic nervous system are not very sensitive and the next step could be to try to use more sensitive physiological indexes, such as central nervous system indexes (e.g., brain waves), as evidence to support the relieving stress effects of soundscapes [128]. The future design of restorative urban park environments should go beyond visual-driven thinking to fully explore and utilise multiple restorative environmental factors from a multi-dimensional perspective, thus providing more convincing evidence for the design of restorative urban park environments.

\section{Conclusions}

In this study, 20 audiovisual videos (10 audio videos and 10 silent videos) of the urban park environments were used as research materials. Thirty five university students were invited to conduct audiovisual experiments, and the physiological indexes of the participants were collected with the help of Ergo LAB data platform, and a soundscape perception evaluation questionnaire was used to assess the degree of soundscape perceptions in the urban park environment sample sites. The aim is to investigate whether urban park environments can relieve stress, the differences in the effects of different urban park environments in relieving stress and the effects of soundscapes in relieving stress in urban parks, and to investigate in depth which soundscapes are important factors in restorative soundscapes (if any positive effects). The main conclusions are as follows:

- In terms of physiological responses, all urban park environments can relieve stress to some extent. 
- There are differences in the relieving stress effects of different urban park environments, with those dominated by natural spaces having better relieving stress effects and those with too many artificial factors or too much seclusion having poorer relieving stress effects.

- The inclusion of soundscapes can change the relieving stress effects of urban park environments, with the exception of urban park environments where conversation sound and children playing sound are more prominent, where a combination of audiovisual stimuli has better relieving stress effects than single visual stimulus.

- Natural sounds such as birdsong, stream sound, cicada sound and wind sound contribute more to relieving stress effects of an urban park, while human-based sounds such as footstep sound do the opposite.

Author Contributions: Conceptualization, X.C. and Y.H.; methodology, X.C.; software, X.C.; validation, X.C. and Y.H.; formal analysis, X.C.; investigation, X.C. and Y.H.; resources, X.C. and Y.H.; data curation, X.C. and Y.H.; writing-original draft preparation, X.C.; writing-review and editing, X.C. and Y.H.; visualization, X.C. and Y.H.; supervision, X.C. and Y.H.; project administration, X.C.; funding acquisition, X.C. All authors have read and agreed to the published version of the manuscript.

Funding: This research received no external funding.

Acknowledgments: The authors thank all participants who participated in our experiment, and ErgoLAB data platform (human-machine environment synchronisation platform developed by Beijing Jinfa Technology Instruments Co.) for the technical support.

Conflicts of Interest: The authors declare no conflict of interest.

\section{References}

1. Kaplan, R.; Kaplan, S. The Experience of Nature: A Psychological Perspective; Cambridge University Press: Cambridge, MA, USA, 1989.

2. Herzog, T.R.; Chen, H.C.; Primeau, J.S. Perception of the restorative potential of natural and other settings. J. Environ. Psychol. 2002, 22, 295-306. [CrossRef]

3. Karmanov, D.; Hamel, R. Assessing the restorative potential of contemporary urban environment(s): Beyond the nature versus urban dichotomy. Landsc. Urban Plan. 2008, 86, 115-125. [CrossRef]

4. ISO. Acoustics. Soundscape-Part 1: Definition and Conceptual Framework; 12913-1, I.D.; International Standardization Organization: Geneva, Switzerland, 2014.

5. He, M.; Pang, H. A review of soundscape research history and progress. Landsc. Archit. 2016, 5, 88-97.

6. Berto, R. Exposure to restorative environments helps restore attentional capacity. J. Environ. Psychol. 2005, 25, 249-259. [CrossRef]

7. Fang, X.; Gao, T.; Hedblom, M.; Xu, N.; Xiang, Y.; Hu, M.; Chen, Y.; Qiu, L. Soundscape perceptions and preferences for different groups of users in urban recreational forest parks. Forests 2021, 12, 468. [CrossRef]

8. Karjalainen, E.; Sarjala, T.; Raitio, H. Promoting human health through forests: Overview and major challenges. Environ. Health Prev. Med. 2010, 15, 1-8. [CrossRef]

9. Scopelliti, M.; Carrus, G.; Adinolfi, C.; Suarez, G.; Colangelo, G.; Lafortezza, R.; Panno, A.; Sanesi, G. Staying in touch with nature and well-being in different income groups: The experience of urban parks in Bogotá. Landsc. Urban Plan. 2016, 148, 139-148. [CrossRef]

10. Peters, K.; Elands, B.; Buijs, A. Social interactions in urban parks: Stimulating social cohesion? Urban For. Urban Green. 2010, 9 , 93-100. [CrossRef]

11. Chiesura, A. The role of urban parks for the sustainable city. Landsc. Urban Plan. 2004, 68, 129-138. [CrossRef]

12. Tsunetsugu, Y.; Lee, J.; Park, B.-J.; Tyrväinen, L.; Kagawa, T.; Miyazaki, Y. Physiological and psychological effects of viewing urban forest landscapes assessed by multiple measurements. Landsc. Urban Plan. 2013, 113, 90-93. [CrossRef]

13. Yu, C.-P.; Lin, C.-M.; Tsai, M.-J.; Tsai, Y.-C.; Chen, C.-Y. Effects of short forest bathing program on autonomic nervous system activity and mood states in middle-aged and elderly individuals. Int. J. Environ. Res. Public Health 2017, 14, 897. [CrossRef]

14. Yu, C.-P.; Lee, H.-Y.; Luo, X.-Y. The effect of virtual reality forest and urban environments on physiological and psychological responses. Urban For. Urban Green. 2018, 35, 106-114. [CrossRef]

15. Hedblom, M.; Gunnarsson, B.; Iravani, B.; Knez, I.; Schaefer, M.; Thorsson, P.; Lundström, J. Reduction of physiological stress by urban green space in a multisensory virtual experiment. Sci. Rep. 2019, 9, 1-11. [CrossRef]

16. Song, C.; Ikei, H.; Miyazaki, Y. Physiological effects of forest-related visual, olfactory, and combined stimuli on humans: An additive combined effect. Urban For. Urban Green. 2019, 44, 126437. [CrossRef]

17. Zhao, Z.; Wang, Y.; Hou, Y. Residents' spatial perceptions of urban gardens based on soundscape and landscape differences. Sustainability 2020, 12, 6809. [CrossRef] 
18. Aletta, F.; Oberman, T.; Kang, J. Associations between positive health-related effects and soundscapes perceptual constructs: A systematic review. Int. J. Environ. Res. Public Health 2018, 15, 2392. [CrossRef]

19. Annerstedt, M.; Jönsson, P.; Wallergård, M.; Johansson, G.; Karlson, B.; Grahn, P.; Hansen, Å.M.; Währborg, P. Inducing physiological stress recovery with sounds of nature in a virtual reality forest-Results from a pilot study. Physiol. Behav. 2013, 118, 240-250. [CrossRef]

20. Jo, H.; Song, C.; Ikei, H.; Enomoto, S.; Kobayashi, H.; Miyazaki, Y. Physiological and Psychological Effects of Forest and Urban Sounds Using High-Resolution Sound Sources. Int. J. Environ. Res. Public Health 2019, 16, 2649. [CrossRef]

21. Medvedev, O.; Shepherd, D.; Hautus, M.J. The restorative potential of soundscapes: A physiological investigation. Appl. Acoust. 2015, 96, 20-26. [CrossRef]

22. Suko, Y.; Saito, K.; Takayama, N.; Warisawa, S.I.; Sakuma, T. Effect of faint road traffic noise mixed in birdsong on the perceived restorativeness and listeners' physi-ological response: An exploratory study. Int. J. Environ. Res. Public Health 2019, 16, 4985. [CrossRef]

23. WHO. Environmental Noise Guidelines for the European Region; WHO: Geneva, Switzerland, 2018.

24. Basner, M.; Babisch, W.; Davis, A.; Brink, M.; Clark, C.; Janssen, S.; Stansfeld, S. Auditory and non-auditory effects of noise on health. Lancet 2014, 383, 1325-1332. [CrossRef]

25. Alvarsson, J.J.; Wiens, S.; Nilsson, M. Stress recovery during exposure to nature sound and environmental noise. Int. J. Environ. Res. Public Health 2010, 7, 1036-1046. [CrossRef]

26. MA, H.; WANG, D.-d. Primary quantification of soundscape elements in urban parks. Noise Vib. Control $2012,1$.

27. Zhao, W.; Li, H.; Zhu, X.; Ge, T. Effect of birdsong soundscape on perceived restorativeness in an urban park. Int. J. Environ. Res. Public Health 2020, 17, 5659. [CrossRef]

28. Conniff, A.; Craig, T. A methodological approach to understanding the wellbeing and restorative benefits associated with greenspace. Urban For. Urban Green. 2016, 19, 103-109. [CrossRef]

29. Jeon, J.Y.; Hong, J.Y.; Lavandier, C.; Lafon, J.; Axelsson, Ö.; Hurtig, M. A cross-national comparison in assessment of urban park soundscapes in France, Korea, and Sweden through laboratory experiments. Appl. Acoust. 2018, 133, 107-117. [CrossRef]

30. Axelsson, Ö. How to measure soundscape quality. In Proceedings of the Euronoise 2015 Conference, Maastricht, The Netherlands, 1-3 June 2015.

31. Aletta, F.; Kang, J. Soundscape approach integrating noise mapping techniques: A case study in Brighton, UK. Noise Mapp. 2015, 2. [CrossRef]

32. Berglund, B.; Nilsson, M.E. On a tool for measuring soundscape quality in urban residential areas. Acta Acust. United Acust. 2006, 92, 938-944.

33. Lavia, L.; Witchel, H.J.; Aletta, F.; Steffens, J.; Fiebig, A.; Kang, J.; Howes, C.; Healey, P.G.T. Non-participant observation methods for soundscape design and urban planning. In Handbook of Research on Industrial Informatics and Manufacturing Intelligence; IGI Global: Hershey, PA, USA, 2018; pp. 73-99.

34. Mitchell, A.; Oberman, T.; Aletta, F.; Erfanian, M.; Kachlicka, M.; Lionello, M.; Kang, J. The soundscape indices (SSID) protocol: A method for urban soundscape surveys-Questionnaires with acoustical and contextual information. Appl. Sci. 2020, 10, 2397. [CrossRef]

35. Kang, J.; Aletta, F.; Margaritis, E.; Yang, M. A model for implementing soundscape maps in smart cities. Noise Mapp. 2018, 5, 46-59. [CrossRef]

36. Aletta, F.; Oberman, T.; Axelsson, Ö.; Xie, H.; Zhang, Y.; Lau, S.K.; Tang, S.K.; Jambrošić, K.; De Coensel, B.; van den Bosch, K.; et al. Soundscape assessment: Towards a validated translation of perceptual attributes in different languages. In Proceedings of the INTER-NOISE and NOISE-CON Congress and Conference, Seoul, Korea, 23-26 August 2020; Institute of Noise Control Engineering: Washington, DC, USA, 2020.

37. Jahncke, H.; Hygge, S.; Halin, N.; Green, A.M.; Dimberg, K. Open-plan office noise: Cognitive performance and restoration. J. Environ. Psychol. 2011, 31,373-382. [CrossRef]

38. Ma, H.; Shu, S. An experimental study: The restorative effect of soundscape elements in a simulated open-plan office. Acta Acust. United Acust. 2018, 104, 106-115. [CrossRef]

39. Van Praag, C.D.G.; Garfinkel, S.N.; Sparasci, O.; Mees, A.; Philippides, A.O.; Ware, M.; Ottaviani, C.; Critchley, H.D. Mindwandering and alterations to default mode network connectivity when listening to naturalistic versus artificial sounds. Sci. Rep. 2017, 7, 1-12.

40. WHO. Urban Green Spaces and Health: A Review of Evidence; World Health Organization: Copenhagen, Denmark, 2016.

41. Theakston, F. Burden of Disease from Environmental Noise: Quantification of Healthy Life Years Lost in Europe; WHO: Geneva, Switzerland, 2011.

42. Kang, J. Urban Sound Environment; CRC Press: Boca Raton, FL, USA, 2006.

43. Jeon, J.Y.; Jo, H.I. Effects of audio-visual interactions on soundscape and landscape perception and their influence on satisfaction with the urban environment. Build. Environ. 2020, 169, 106544. [CrossRef]

44. Liu, J.; Wang, Y.; Zimmer, C.; Kang, J.; Yu, T. Factors associated with soundscape experiences in urban green spaces: A case study in Rostock, Germany. Urban For. Urban Green. 2019, 37, 135-146. [CrossRef]

45. Kang, J.; Aletta, F.; Gjestland, T.T.; Brown, L.A.; Botteldooren, D.; Schulte-Fortkamp, B.; Lercher, P.; van Kamp, I.; Genuit, K.; Fiebig, A.; et al. Ten questions on the soundscapes of the built environment. Build. Environ. 2016, 108, 284-294. [CrossRef] 
46. Fiebig, A.; Guidati, S.; Goehrke, A. Psychoacoustic Evaluation of Traffic Noise; NAG, DAGA: Roterdam, The Netherlands, 2009.

47. Aletta, F.; Kang, J.; Axelsson, Ö. Soundscape descriptors and a conceptual framework for developing predictive soundscape models. Landsc. Urban Plan. 2016, 149, 65-74. [CrossRef]

48. Papadimitriou, K.D.; Mazaris, A.D.; Kallimanis, A.S.; Pantis, J.D. Cartographic representation of the sonic environment. Cartogr. J. 2009, 46, 126-135. [CrossRef]

49. Vogiatzis, K.; Remy, N. From environmental noise abatement to soundscape creation through strategic noise mapping in medium urban agglomerations in South Europe. Sci. Total. Environ. 2014, 482-483, 420-431. [CrossRef]

50. Flint, T.; Turner, P.; Leplâtre, G.; McGregor, I. Soundscape Mapping: A Tool for Evaluating Sounds and Auditory Environments; Georgia Institute of Technology: Atlanta, GA, USA, 2010.

51. Marry, S. Assessment of urban soundscapes. Organ. Sound 2011, 16, 245-255. [CrossRef]

52. Aletta, F.; Guattari, C.; Evangelisti, L.; Asdrubali, F.; Oberman, T.; Kang, J. Exploring the compatibility of "Method A" and "Method B" data collection protocols reported in the ISO/TS 12913-2: 2018 for urban soundscape via a soundwalk. Appl. Acoust. 2019, 155, 190-203. [CrossRef]

53. Butler, T. A walk of art: The potential of the sound walk as practice in cultural geography. Soc. Cult. Geogr. 2006, 7, 889-908. [CrossRef]

54. Jeon, J.Y.; Hong, J.; Lee, P.J. Soundwalk approach to identify urban soundscapes individually. J. Acoust. Soc. Am. 2013, 134, 803-812. [CrossRef]

55. Adams, M.D.; Bruce, N.S.; Davies, W.J.; Cain, R.; Jennings, P.; Carlyle, A.; Cusack, P.; Hume, K.; Plack, C. Soundwalking as a methodology for understanding soundscapes. In Proceedings of the Institute of Acustics Spring Conference 2008, Reading, UK, 10-11 April 2008.

56. Aletta, F.; Margaritis, E.; Filipan, K.; Romero, V.P.; Axelsson, Ö.; Kang, J. Characterization of the soundscape in Valley Gardens, Brighton, by a soundwalk prior to an urban design intervention. In Proceedings of the Euronoise Conference, Maastricht, The Netherlands, 31 May-3 June 2015. Unpublished.

57. Jaszczak, A.; Małkowska, N.; Kristianova, K.; Bernat, S.; Pochodyła, E. Evaluation of soundscapes in urban parks in Olsztyn (Poland) for improvement of landscape design and management. Land 2021, 10, 66. [CrossRef]

58. Lam, K.-C.; Ng, S.-L.; Hui, W.-C.; Chan, P.-K. Environmental quality of urban parks and open spaces in Hong Kong. Environ. Monit. Assess. 2005, 111, 55-73. [CrossRef]

59. Payne, S.R. Are perceived soundscapes within urban parks restorative. J. Acoust. Soc. Am. 2008, 123, 3809. [CrossRef]

60. Andersson, E.M.; Ögren, M.; Molnár, P.; Segersson, D.; Rosengren, A.; Stockfelt, L. Road traffic noise, air pollution and cardiovascular events in a Swedish cohort. Environ. Res. 2020, 185, 109446. [CrossRef]

61. Watts, G.; Pheasant, R.; Horoshenkov, K. Tranquil spaces in a metropolitan area. In Proceedings of the 20th International Congress on Acoustics, Sydney, Australia, 23-27 August 2010.

62. Sanchez, G.M.E.; Van Renterghem, T.; Thomas, P.; Botteldooren, D. The effect of street canyon design on traffic noise exposure along roads. Build. Environ. 2016, 97, 96-110. [CrossRef]

63. Van Renterghem, T.; Forssén, J.; Attenborough, K.; Jean, P.; Defrance, J.; Hornikx, M.; Kang, J. Using natural means to reduce surface transport noise during propagation outdoors. Appl. Acoust. 2015, 92, 86-101. [CrossRef]

64. Van Renterghem, T.; Vanhecke, K.; Filipan, K.; Sun, K.; De Pessemier, T.; De Coensel, B.; Joseph, W.; Botteldooren, D. Interactive soundscape augmentation by natural sounds in a noise polluted urban park. Landsc. Urban Plan. 2020, 194, 103705. [CrossRef]

65. Hong, J.Y.; Ong, Z.-T.; Lam, B.; Ooi, K.; Gan, W.-S.; Kang, J.; Feng, J.; Tan, S.-T. Effects of adding natural sounds to urban noises on the perceived loudness of noise and soundscape quality. Sci. Total Environ. 2020, 711, 134571. [CrossRef]

66. Kang, J. From dBA to soundscape indices: Managing our sound environment. Front. Eng. Manag. 2017, 4, 184-192. [CrossRef]

67. Gozalo, G.R.; Morillas, J.M.B.; González, D.M.; Moraga, P.A. Relationships among satisfaction, noise perception, and use of urban green spaces. Sci. Total Environ. 2018, 624, 438-450. [CrossRef] [PubMed]

68. Gozalo, G.R.; Morillas, J.M.B. Perceptions and effects of the acoustic environment in quiet residential areas. J. Acoust. Soc. Am. 2017, 141, 2418-2429. [CrossRef] [PubMed]

69. Yu, L.; Kang, J. Factors influencing the sound preference in urban open spaces. Appl. Acoust. 2010, 71, 622-633. [CrossRef]

70. Viollon, S.; Lavandier, C.; Drake, C. Influence of visual setting on sound ratings in an urban environment. Appl. Acoust. 2002, 63, 493-511. [CrossRef]

71. Kang, J.; Zhang, M. Semantic differential analysis of the soundscape in urban open public spaces. Build. Environ. 2010, 45, 150-157. [CrossRef]

72. Yu, L.; Kang, J. Effects of social, demographical and behavioral factors on the sound level evaluation in urban open spaces. J. Acoust. Soc. Am. 2008, 123, 772-783. [CrossRef]

73. Sang, Å.O.; Knez, I.; Gunnarsson, B.; Hedblom, M. The effects of naturalness, gender, and age on how urban green space is perceived and used. Urban For. Urban Green. 2016, 18, 268-276. [CrossRef]

74. Alves, S.; Estévez-Mauriz, L.; Aletta, F.; Echevarria-Sanchez, G.M.; Romero, V.P. Towards the integration of urban sound planning in urban development processes: The study of four test sites within the SONORUS project. Noise Mapp. 2015, 2. [CrossRef]

75. Van Kempen, E.; Devilee, J.; Swart, W.; Van Kamp, I. Characterizing urban areas with good sound quality: Development of a research protocol. Noise Health 2014, 16, 380-387. [CrossRef] 
76. Muratet, A.; Pellegrini, P.; Dufour, A.-B.; Arrif, T.; Chiron, F. Perception and knowledge of plant diversity among urban park users. Landsc. Urban Plan. 2015, 137, 95-106. [CrossRef]

77. Hunter, I. What do people want from urban forestry?-The European experience. Urban Ecosyst. 2001, 5, 277-284. [CrossRef]

78. Coles, R.; Bussey, S. Urban forest landscapes in the UK-Progressing the social agenda. Landsc. Urban Plan. 2000, 52, 181-188. [CrossRef]

79. Pereira, E.; Queiroz, C.; Pereira, H.; Vicente, L. Ecosystem services and human well-being: A participatory study in a mountain community in Portugal. Ecol. Soc. 2005, 10, 14. [CrossRef]

80. Modelmog, I. 'Nature'as a promise of happiness: Farmers' wives in the area of Ammerland, Germany. Sociol. Rural 1998, 38, 109-122. [CrossRef]

81. Ratcliffe, E.; Gatersleben, B.; Sowden, P.T. Bird sounds and their contributions to perceived attention restoration and stress recovery. J. Environ. Psychol. 2013, 36, 221-228. [CrossRef]

82. Cerwén, G.; Pedersen, E.; Pálsdóttir, A.-M. The role of soundscape in nature-based rehabilitation: A patient perspective. Int. J. Environ. Res. Public Health 2016, 13, 1229. [CrossRef]

83. Liu, J.; Kang, J.; Luo, T.; Behm, H. Landscape effects on soundscape experience in city parks. Sci. Total Environ. 2013, 454-455, 474-481. [CrossRef]

84. Fields, J.M. Effect of personal and situational variables on noise annoyance in residential areas. J. Acoust. Soc. Am. 1993, 93, 2753-2763. [CrossRef]

85. Liu, J.; Xiong, Y.; Wang, Y.; Luo, T. Soundscape effects on visiting experience in city park: A case study in Fuzhou, China. Urban For. Urban Green. 2018, 31, 38-47. [CrossRef]

86. Meng, Q.; Kang, J. The influence of crowd density on the sound environment of commercial pedestrian streets. Sci. Total Environ. 2015, 511, 249-258. [CrossRef] [PubMed]

87. Meng, Q.; Ren, P.W.; Liao, W.Q. Effect of users' social characteristics on soundscape in the waiting halls of railway stations. Adv. Mater. Res. 2012, 518-523, 3805-3808. [CrossRef]

88. Tse, M.S.; Chau, C.-K.; Choy, Y.S.; Tsui, W.K.; Chan, C.N.; Tang, S. Perception of urban park soundscape. J. Acoust. Soc. Am. 2012, 131, 2762-2771. [CrossRef] [PubMed]

89. Jo, H.I.; Jeon, J.Y. The influence of human behavioral characteristics on soundscape perception in urban parks: Subjective and observational approaches. Landsc. Urban Plan. 2020, 203, 103890. [CrossRef]

90. $\mathrm{Xu}, \mathrm{X} . ; \mathrm{Wu}, \mathrm{H}$. Audio-visual interactions enhance soundscape perception in China's protected areas. Urban For. Urban Green. 2021, 61, 127090. [CrossRef]

91. Ma, K.W.; Mak, C.M.; Wong, H.M. Effects of environmental sound quality on soundscape preference in a public urban space. Appl. Acoust. 2021, 171, 107570. [CrossRef]

92. Shu, S.; Ma, H. Restorative effects of urban park soundscapes on children's psychophysiological stress. Appl. Acoust. 2020, 164, 107293. [CrossRef]

93. Huang, B.-X.; Chiou, S.-C.; Li, W.-Y. Landscape pattern and ecological network structure in urban green space planning: A case study of Fuzhou City. Land 2021, 10, 769. [CrossRef]

94. Klenke, K. Qualitative Research in the Study of Leadership; Emerald Group Publishing: Bingley, UK, 2008.

95. Steele, D.; Bild, E.; Tarlao, C.; Guastavino, C. Soundtracking the public space: Outcomes of the Musikiosk soundscape intervention. Int. J. Environ. Res. Public Health 2019, 16, 1865. [CrossRef]

96. Jeon, J.Y.; Jo, H.I. Three-dimensional virtual reality-based subjective evaluation of road traffic noise heard in urban high-rise residential buildings. Build. Environ. 2019, 148, 468-477. [CrossRef]

97. Jo, H.I.; Jeon, J.Y. Downstairs resident classification characteristics for upstairs walking vibration noise in an apartment building under virtual reality environment. Build. Environ. 2019, 150, 21-32. [CrossRef]

98. Jeon, J.Y.; Jo, H.I.; Kim, S.M.; Yang, H.S. Subjective and objective evaluation of water-supply and drainage noises in apartment buildings by using a head-mounted display. Appl. Acoust. 2019, 148, 289-299. [CrossRef]

99. Hong, J.Y.; Lam, B.; Ong, Z.T.; Ooi, K.; Gan, W.S.; Kang, J.; Feng, J.; Tan, S.T. Quality assessment of acoustic environment reproduction methods for cinematic virtual reality in sound-scape applications. Build. Environ. 2019, 149, 1-14. [CrossRef]

100. Sanchez, G.M.E.; Van Renterghem, T.; Sun, K.; De Coensel, B.; Botteldooren, D. Using virtual reality for assessing the role of noise in the audio-visual design of an urban public space. Landsc. Urban Plan. 2017, 167, 98-107. [CrossRef]

101. Liu, F.; Kang, J. Relationship between street scale and subjective assessment of audio-visual environment comfort based on 3D virtual reality and dual-channel acoustic tests. Build. Environ. 2018, 129, 35-45. [CrossRef]

102. Luigi, M.; Massimiliano, M.; Aniello, P.; Gennaro, R.; Virginia, P.R. On the validity of immersive virtual reality as tool for multisensory evaluation of urban spaces. Energy Procedia 2015, 78, 471-476. [CrossRef]

103. Hong, J.Y.; He, J.; Lam, B.; Gupta, R.; Gan, W.-S. Spatial audio for soundscape design: Recording and reproduction. Appl. Sci. 2017, 7, 627. [CrossRef]

104. Puyana-Romero, V.; Lopez-Segura, L.S.; Maffei, L.; Hernández-Molina, R.; Masullo, M. Interactive soundscapes: $360^{\circ}$-video based immersive virtual reality in a tool for the participatory acoustic environment evaluation of urban areas. Acta Acust. United Acust. 2017, 103, 574-588. [CrossRef]

105. Maffei, L.; Masullo, M.; Pascale, A.; Ruggiero, G.; Romero, V.P. Immersive virtual reality in community planning: Acoustic and visual congruence of simulated vs real world. Sustain. Cities Soc. 2016, 27, 338-345. [CrossRef] 
106. Zurlo, M.C.; Cattaneo Della Volta, M.F.; Vallone, F. COVID-19 Student stress questionnaire: Development and validation of a questionnaire to evaluate students' stressors related to the coronavirus pandemic lockdown. Front. Psychol. 2020, $11,2892$. [CrossRef]

107. Fawaz, M.; Samaha, A. E-learning: Depression, anxiety, and stress symptomatology among Lebanese university students during COVID-19 quarantine. Nurs. Forum 2021, 56, 52-57. [CrossRef]

108. Stamps, A.E. Demographic effects in environmental aesthetics: A meta-analysis. J. Plan. Lit. 1999, 14, 155-175. [CrossRef]

109. Hume, K.; Ahtamad, M. Physiological responses to and subjective estimates of soundscape elements. Appl. Acoust. 2013, 74, 275-281. [CrossRef]

110. Hedblom, M.; Gunnarsson, B.; Schaefer, M.; Knez, I.; Thorsson, P.; Lundström, J.N. Sounds of nature in the city: No evidence of bird song improving stress recovery. Int. J. Environ. Res. Public Health 2019, 16, 1390. [CrossRef]

111. Jing, C.; Zhi, J.; Yang, S.; Wang, W. Impact of driver age and experience in software usage on driving safety and usability of car-sharing software. J. Adv. Transp. 2021, 2021, 1-14. [CrossRef]

112. Elsadek, M.; Shao, Y.; Liu, B. Benefits of indirect contact with nature on the physiopsychological well-being of elderly people. HERD Health Environ. Res. Des. J. 2021, 14, 227-241. [CrossRef]

113. Zhou, Z.; Cheng, J.; Wei, W.; Lee, L. Validation of evaluation model and evaluation indicators comprised Kansei Engineering and eye movement with EEG: An example of medical nursing bed. Microsyst. Technol. 2021, 27, 1317-1333. [CrossRef]

114. Li, Z.; Kang, J. Sensitivity analysis of changes in human physiological indicators observed in soundscapes. Landsc. Urban Plan. 2019, 190, 103593. [CrossRef]

115. Vescio, B.; Salsone, M.; Gambardella, A.; Quattrone, A. Comparison between electrocardiographic and earlobe pulse photoplethysmographic detection for evaluating heart rate variability in healthy subjects in short- and long-term recordings. Sensors 2018, 18, 844. [CrossRef]

116. Ratcliffe, E. Sound and soundscape in restorative natural environments: A narrative literature review. Front. Psychol. 2021, $12,963$. [CrossRef] [PubMed]

117. Nilsson, M.E.; Berglund, B. Soundscape quality in suburban green areas and city parks. Acta Acust. United Acust. 2006, 92, 903-911.

118. Shu, S.; Ma, H. Restorative effects of classroom soundscapes on children's cognitive performance. Int. J. Environ. Res. Public Health 2019, 16, 293. [CrossRef] [PubMed]

119. Wang, X.; Shi, Y.; Zhang, B.; Chiang, Y. The influence of forest resting environments on stress using virtual reality. Int. J. Environ. Res. Public Health 2019, 16, 3263. [CrossRef]

120. Ulrich, R.S.; Simons, R.F.; Losito, B.D.; Fiorito, E.; Miles, M.A.; Zelson, M. Stress recovery during exposure to natural and urban environments. J. Environ. Psychol. 1991, 11, 201-230. [CrossRef]

121. Ratcliffe, E.; Gatersleben, B.; Sowden, P.T. Associations with bird sounds: How do they relate to perceived restorative potential? J. Environ. Psychol. 2016, 47, 136-144. [CrossRef]

122. Watts, G.R.; Pheasant, R.J.; Horoshenkov, K.V.; Ragonesi, L. Measurement and subjective assessment of water generated sounds. Acta Acust. United Acust. 2009, 95, 1032-1039. [CrossRef]

123. White, M.; Smith, A.; Humphryes, K.; Pahl, S.; Snelling, D.; Depledge, M. Blue space: The importance of water for preference, affect, and restorativeness ratings of natural and built scenes. J. Environ. Psychol. 2010, 30, 482-493. [CrossRef]

124. Deng, L.; Luo, H.; Ma, J.; Huang, Z.; Sun, L.-X.; Jiang, M.-Y.; Zhu, C.-Y.; Li, X. Effects of integration between visual stimuli and auditory stimuli on restorative potential and aesthetic preference in urban green spaces. Urban For. Urban Green. 2020, 53, 126702. [CrossRef]

125. White, M.P.; Pahl, S.; Ashbullby, K.; Herbert, S.; Depledge, M.H. Feelings of restoration from recent nature visits. J. Environ. Psychol. 2013, 35, 40-51. [CrossRef]

126. Jeon, J.Y.; Lee, P.J.; You, J.; Kang, J. Acoustical characteristics of water sounds for soundscape enhancement in urban open spaces. J. Acoust. Soc. Am. 2012, 131, 2101-2109. [CrossRef]

127. Tedja, Y.W.; Tsaih, L. Water soundscape and listening impression. In Proceedings of Meetings on Acoustics 170ASA. J. Acoust. Soc. Am. 2015, 138, 1750. [CrossRef]

128. Lin, W.; Chen, Q.; Zhang, X.; Tao, J.; Liu, Z.; Lyu, B.; Li, N.; Li, D.; Zeng, C. Effects of different bamboo forest spaces on psychophysiological stress and spatial scale evaluation. Forests 2020, 11, 616. [CrossRef] 